\title{
1 Regional Scale Cropland Carbon Budgets: Evaluating a Geospatial 2 Agricultural Modeling System Using Inventory Data
}

4 Xuesong Zhang ${ }^{1}$, Roberto C. Izaurralde ${ }^{2,6}$, David H. Manowitz ${ }^{1}$, Ritvik Sahajpal ${ }^{2}$, Tristram O.

5 West $^{1}$, Allison M. Thomson ${ }^{1}$, Min Xu ${ }^{3}$, Kaiguang Zhao ${ }^{4}$, Stephen D. LeDuc ${ }^{5}$, Jimmy R. 6 Williams $^{6}$

$7 \quad{ }^{1}$ Joint Global Change Research Institute, Pacific Northwest National Laboratory and University 8 of Maryland, College Park, MD 20740, USA;

$9{ }^{2}$ Department of Geographical Sciences, University of Maryland, College Park, MD 20740, USA, $10{ }^{3}$ Earth System Science Interdisciplinary Center, University of Maryland, College Park, MD 11 20740, USA;

$12{ }^{4}$ School of Environment and Natural Resources, the Ohio Agricultural Research and

13 Development Center, Ohio State University, Wooster, OH 44691, USA;

$14{ }^{5}$ U.S. Environmental Protection Agency, National Center for Environmental Assessment, 15 Arlington VA 22202, USA;

$16{ }^{6}$ Texas A\&M AgriLife Research \& Extension Center, 720 E. Blackland Road Temple, TX 17 76502, USA. 
Abstract. Accurate quantification and clear understanding of regional scale cropland carbon (C) cycling is critical for designing effective policies and management practices that can contribute toward stabilizing atmospheric $\mathrm{CO}_{2}$ concentrations. However, extrapolating site-scale observations to regional scales represents a major challenge confronting the agricultural modeling community. This study introduces a novel geospatial agricultural modeling system (GAMS) exploring the integration of the mechanistic Environmental Policy Integrated Climate model, spatially-resolved data, surveyed management data, and supercomputing functions for cropland $\mathrm{C}$ budgets estimates. This modeling system creates spatially-explicit modeling units at a spatial resolution consistent with remotely-sensed crop identification and assigns cropping systems to each of them by geo-referencing surveyed crop management information at the county or state level. A parallel computing algorithm was also developed to facilitate the computationally intensive model runs and output post-processing and visualization. We evaluated GAMS against National Agricultural Statistics Service (NASS) reported crop yields and inventory estimated county-scale cropland C budgets averaged over 2000-2008. We observed good overall agreement, with spatial correlation of $0.89,0.90,0.41$, and 0.87 , for crop yields, Net Primary Production (NPP), Soil Organic C (SOC) change, and Net Ecosystem Exchange (NEE), respectively. However, we also detected notable differences in the magnitude of NPP and NEE, as well as in the spatial pattern of SOC change. By performing crop-specific annual comparisons, we discuss possible explanations for the discrepancies between GAMS and the inventory method, such as data requirements, representation of agroecosystem processes, completeness and accuracy of crop management data, and accuracy of crop area representation. Based on these analyses, we further discuss strategies to improve GAMS by updating input data and by designing more efficient parallel computing capability to quantitatively assess errors associated with the simulation of $\mathrm{C}$ budget components. The modularized design of the GAMS 43 makes it flexible to be updated and adapted for different agricultural models so long as they 44 require similar input data, and to be linked with socio-economic models to understand the 45 effectiveness and implications of diverse $\mathrm{C}$ management practices and policies.

46 Keywords. Agriculture, Carbon, Climate change, EPIC, geospatial modeling, and parallel 47 computing 


\section{Introduction}

Agroecosystems not only provide essential life-supporting goods (e.g. food, fuel, livestock, and fiber) for humans, but also hold the promise to sequester carbon dioxide $\left(\mathrm{CO}_{2}\right)$ and other greenhouse gases (GHGs), thereby mitigating potential negative impacts of future climate change (Lal and Bruce, 1999; Paustian et al., 2006; Smith et al., 2007). The potential impact of changing farming practices for global emissions of GHGs has been widely recognized (UNEP, 2013). Agricultural technologies and practices can potentially mitigate $\sim 5.5-6.0 \mathrm{Pg} \mathrm{CO}_{2}$-eq $\mathrm{yr}^{-1}$ emissions at the global scale (Smith et al., 2007). The significant magnitude of this mitigation potential makes it necessary to consider physical, chemical, and biological dynamics of managed landscapes when understanding, quantifying, and regulating the global carbon (C) cycle (Moureaux et al., 2008; Sus et al., 2010).

The development of effective measures to stabilize atmospheric $\mathrm{CO}_{2}$ concentration requires accurate quantification of the spatial variation and magnitude of $\mathrm{C}$ flux. Due to the lack of systematic and extensive collection of $\mathrm{C}$ budget observations, modeling approaches have been often used by researchers and decision makers (Saby et al., 2008; Ogle et al., 2010; West et al., 2010). A suite of modeling tools and methods operating at national or regional scales have been developed to estimate soil organic $\mathrm{C}$ (SOC) change and/or land-atmosphere $\mathrm{C}$ exchange by using inventory statistics, computer simulation models, satellite remote sensing products, geographic information systems, and/or eddy covariance flux tower measurements (Post et al., 2001; Whittaker et al., 2013). For example, an inventory method (West et al., 2008; West et al., 2010) was developed to estimate county-scale harvested biomass C, net primary production (NPP), SOC inputs and decomposition, and net ecosystem exchange (NEE), as well as agronomic production emissions of GHGs from seeding, tillage, fertilizer application, and harvesting. This inventory method is heavily rooted in the integration of U.S. Department of Agriculture's (USDA) National Agricultural Statistics Service (NASS) surveyed crop yields, State Soil Geographic (STATSGO) data (USDA-NRCS, 1995), and empirical relationships between SOC dynamics and diverse crop management practices derived from hundreds of field experimental sites. This data-rich and fine-scale approach has been recognized as a benchmark for cropland $\mathrm{C}$ budgets in several compelling model intercomparison and $\mathrm{C}$ budget synthesis projects, including the North American Carbon Program's (NACP) Midcontinent Mid-Continent Intensive (MCI) 
78 Campaign (Ogle and Davis, 2006; Schuh et al., 2013) and Regional Interim Synthesis (Hayes et 79 al., 2012; Huntzinger et al., 2012). Despite the strength of the inventory approach in reliably quantifying the flux of $\mathrm{C}$ from ecosystems, the lack of detailed representation of the mechanisms regulating crop growth and development, water and biogeochemical cycling, and human interventions, limits its role in understanding the feedbacks among land use, climate change, and C cycling (Smith et al., 2012).

The study of complex agroecosytem relationships is best approached through process-based model analyses in combination with experimental data and field monitoring. Mechanistic agroecosystem models are being suggested as an important component of an integrated global framework for soil C monitoring and assessment (Smith et al., 2012). For example, a framework by Ogle et al., (2010) used the process-based CENTURY ecosystem model (Parton et al., 1994), operating at the monthly time step, to estimate SOC changes on the US croplands from 1990 to 2000. Their modeling system employed 121,000 National Resources Inventory (NRI) sampling sites across the US and integrated tillage practices, fertilization, soil types and edaphic characteristics, and climate variations. The point scale simulations were generalized to the scale of major land resource areas (MLRA) for reporting SOC change. The Environmental Policy Integrated Climate (EPIC) model (Williams and Singh, 1995) was tested at eighteen sites in Iowa and incorporated into a geospatial modeling system to simulate SOC change over the Iowa croplands (Causarano et al., 2008). Their modeling system used the Soil Survey Geographic (SSURGO) data that contains more detailed soil survey maps than STATSGO and a Landsat based cropland map at a resolution of $30 \mathrm{~m}$, but aggregated them into a composite layer of $250 \mathrm{~m}$ to explicitly define EPIC modeling units. They simulated a typical corn-soybean rotation characterized with three types of tillage practices at the state-level. Their simulations were evaluated against state-level NASS surveyed corn and soybean yields. These studies consistently demonstrated the importance of using mechanistic models and highlighted the promise of using fine-scale spatial and intensive management information for accounting cropland $\mathrm{C}$ budgets (Smith et al., 2012).

The continuous development of spatial data for climate, terrain, crop classification, and soils has resulted in dramatic increase in spatially-explicit information, thereby providing new opportunities to further advance the application of process-based models. However, as most 
management data, such as tillage and fertilization, are not available in a spatially-explicit way, it is risky to assume that the performance of these models at the site level transfers to the regional scales. Recent studies (Zhang et al., 2013b; Zhang et al., 2014) showed that C flux simulated by process-based models is sensitive to the accuracy and completeness of crop management data, as well as the resolution of soil data. In addition, process-based models demand many more parameterization and data preparation efforts than inventory approaches, rendering them prone to more sources of uncertainty. The lack of extensive evaluation of the process-based models at the regional scales makes it difficult to assess their credibility for large-scale $\mathrm{C}$ budget estimates, thus limiting their role in developing effective $\mathrm{C}$ management practices.

Our objective, therefore, was to describe and test a geospatial agricultural modeling system (GAMS) that integrates the process-based EPIC model with spatially-explicit climate, soils, land use, terrain data, and surveyed crop management data (including fertilization, tillage, planting, and harvesting) to characterize cropping systems in the US Midwest. GAMS operates at a spatial resolution of $56 \mathrm{~m}$ that is consistent with the recently developed Crop Data Layer (CDL) (Johnson and Mueller, 2010). GAMS contains a Geographic Information System (GIS), a proven tool for geospatial data processing and management in regional scale environmental modeling (Rao et al., 2000; Schaldach and Alcamo, 2006; Liu, 2009; Wang et al., 2010). To facilitate model implementation and results processing at such a high resolution, it is also equipped with a parallel computing component and a relational database that is compatible with multi-threading model execution, data processing, and analysis.

We selected the US Midwest as the study area to examine the performance of GAMS (Figure 1). Agroecosystems in the Midwest provide $>85 \%,>80 \%$, and $>50 \%$ of total maize, soybean and wheat production in the entire US (USDA-NASS, 2011) and, concomitantly provide $\sim 60 \%$, $\sim 45 \%$, and $\sim 20 \%$ of world trade in these crops (USDA-ERS, 2010). This highly productive agricultural area is a hotspot of cropland C sequestration in the US (West et al., 2010) and contains biofuel production activities aimed at enhancing energy security and GHG mitigation (EISA, 2007; NRC, 2011; USGCRP, 2012). These dimensions combined make the US Midwest 135 an ideal test bed for applying and assessing GAMS. 
As EPIC has been extensively tested for cropland C budget simulation at the site scale (e.g. (Wang et al., 2005; He et al., 2006; Izaurralde et al., 2006; Causarano et al., 2007; Izaurralde et al., 2007; Causarano et al., 2008; Apezteguía et al., 2009; Schwalm et al., 2010; Zhang et al., 2013b), this research focused on assessing its performance at the county-scale against NASSsurveyed harvested biomass and cropland $\mathrm{C}$ budgets estimated by an inventory approach (West et al., 2010). Although this inventory method has been used as a benchmark in numerous model intercomparisons and C budget syntheses, its estimates of NPP, NEE, and SOC change have not been independently corroborated at the county scale with other process-based agro-ecosystem models. Thus, this comparison not only serves as an evaluation of the EPIC's county-scale estimates, but also provides an independent confirmation of the inventory method. Besides evaluating GAMS for multi-year average total cropland $\mathrm{C}$ flux, we also analyzed results for individual plant species and years. Overall, although GAMS exhibited a high degree of agreement with county-scale NASS crop yield data and inventory estimates (West et al., 2010), noticeable discrepancies were observed, particularly at the level of individual crop species and annual scale evaluations. Based on these spatial and temporal analyses, we identify possible causes for the inconsistencies and uncertainties in GAMS and discuss strategies for further enhancing its performance and promoting its uses in cropland $\mathrm{C}$ management.

\section{Materials and Methods}

\subsection{Overall framework design}

GAMS contains three components (Figure 2). A Geographic Information System (GIS) that fuses multi-source data to prepare spatially-explicit map units and derive each unit's climate, management, soil, land use, and terrain attributes. The employment of high-resolution land use and soil maps in defining homogeneous spatial modeling units (HSMUs) results in ca. 2 million units and ca. 15 million input-output files for cropland in the US Midwest. This requires super computing resources in order to efficiently execute EPIC and analyze results. These EPIC compliant input files are fed into a Python-based parallel computing package, which simultaneously employs hundreds of processors to execute EPIC on the Pacific Northwest National Laboratory's (PNNL) Evergreen computing cluster. The simulation variables are sorted out and stored in online PostgreSQL relational databases and can be easily queried and linked to 
geospatial data for thematic mapping, summarization, and verification. The three components of GAMS are loosely coupled, rather than wrapped in an integrated software package. This flexible configuration allows GAMS to be modified and/or extended for other modeling exercises and analyses.

\subsection{Description of EPIC}

The EPIC model has been extensively tested for many agricultural cropping systems landscapes, and applied worldwide to examine agronomic and environmental impacts of alternative management practices and climate change (Wang et al., 2012). EPIC is a comprehensive terrestrial ecosystem model capable of simulating key biophysical and biogeochemical processes, such as plant growth and development, water balance, $\mathrm{C}$ and nutrient cycling, soil erosion, and greenhouse-gas emissions; and how these processes are influenced by climate conditions, landscape configurations, soil properties, and management practices. The plant growth sub-model of EPIC is a revised version of Crop Environment REsource Synthesis (CERES) (Williams et al., 1989; Jones et al., 1991), employing the concept of radiation-use efficiency by which a fraction of daily photosynthetically-active solar radiation is intercepted by the plant canopy and converted into plant biomass. Daily gains in plant biomass are affected by vapor pressure deficits, atmospheric $\mathrm{CO}_{2}$ concentrations, nutrients availability, and other environmental controls and stresses. Currently, EPIC is parameterized for approximately 120 plant species including food crops, native grasses, and trees. EPIC's hydrology module contains all salient terrestrial water cycling processes including snowmelt, surface runoff, infiltration, soil water content, percolation, lateral flow, water table dynamics, and evapotranspiration. EPIC's biogeochemical module is a modified version of the CENTURY model describing decomposition and transformation of soil $\mathrm{C}$ and nitrogen $(\mathrm{N})$ (Izaurralde et al., 2006) as regulated by many factors and processes, such as soil texture, $\mathrm{pH}$, crop yields, atmospheric $\mathrm{N}$ input, fertilizer and manure, and tillage, among others.

The crop growth and SOC algorithms of EPIC have been examined against field observations from numerous sites across the world (Wang et al., 2005; He et al., 2006; Izaurralde et al., 2006; Causarano et al., 2007; Izaurralde et al., 2007; Causarano et al., 2008; Apezteguía et al., 2009; Schwalm et al., 2010; Zhang et al., 2013b). Its robust performance has made it a useful tool for assessing conservation effects of the Conservation Reserve Program (CRP) (USDA-FSA, 2008, 
2010). Recent studies (Schwalm et al., 2010; Zhang et al., 2013) showed that the $C$ algorithm in EPIC simulated well NEE of diverse agroecosystems in the Midwest, where NEE was calculated as heterotrophic soil respiration minus the net $\mathrm{C}$ sequestration from the atmosphere into plant biomass (i.e. NPP) and is opposite in sign to Net Ecosystem Production (NEP) (Chapin III et al., 2006). A negative sign of NEE indicates $C$ sequestration into biosphere, while a positive one denotes emission into the atmosphere. Here, we focus on the biogenic-related cropland $\mathrm{C}$ processes included in the NEE calculation but do not consider fossil fuel $\mathrm{C}$ emission from agronomic practices and heterotrophic respiration by humans and livestock (West et al., 2011).

Key parameters and initial state variables need to be determined before running models. One parameterization strategy that has been adopted in multiple model assessment and intercomparison projects (Schwalm et al., 2010; Srinivasan et al., 2010) consists of parameterizing variables based on prior information (e.g. from literature or field experiments) without attempting to extensively calibrate parameters to match observed variables of interest. In this case, model performance is highly dependent on the quality of input data. Therefore, we did not modify the default crop, hydrologic, and biogeochmical parameters within EPIC (Williams et al. 1995), but focused on deriving data-based agroecosytem parameters to characterize cropping systems across the Midwest US and using extensively state-of-the-art geospatial data to drive EPIC. Detailed description of the data used and parameterization procedures is presented in the following section.

\section{$214 \quad 2.3$ Fusing spatially-explicit and multi-scale surveyed data into EPIC}

215 We expanded the spatially explicit modeling system from the nine county area previously 216 examined (Zhang et al., 2010) to operate across the entire US Midwest. In so doing, we 217 performed the following efforts: processing SSURGO soil map and attribute data, replacing a 218 uniform crop rotation pattern with spatially-explicit crop sequences derived from multi-year 219 CDL data, and compiling North- American Land Data Assimilation System 2 (NLDAS2, 220 ldas.gsfc.nasa.gov/nldas) climate data.

221 We compiled a series of geospatial databases, including land use / land cover, soil, catchment 222 and political boundaries, and topography data, to define homogeneous spatial modeling units 
(HSMUs) and provide relevant parameters to drive the EPIC model. We used the following geospatial layers:

Crop rotation map. To create crop rotation maps for the US Midwest, we used a method developed using ArcPy in the ArcGIS environment to combine multi-year CDLs and select representative crop rotations (Sahajpal et al., 2014). We used four years of CDL data from 20072010 and for each state identified dominant rotation classes that account for over $85 \%$ of the spatial and temporal crop patterns in the US Midwest. This simplification lowered the total number of crop rotations from 115,425 to around 200, greatly reducing redundancy and computational burden at a relatively low cost inaccuracy.

Soils. The county-scale vector SSURGO maps downloaded from the US Department of Agriculture (USDA) Geospatial Data Gateway (datagateway.nrcs.usda.gov) were merged and converted into a raster format with a resolution of $56 \mathrm{~m}$, consistent with the CDL. Soil properties processed for EPIC included the number of soil layers; layer depth; slope gradient and length; albedo; bulk density; $\mathrm{pH}$; percent sand, silt, clay and coarse fragments; and percent organic $\mathrm{C}$ and total $\mathrm{N}$.

Topography. The Shuttle Radar Topography Mission (SRTM), which produced a digital elevation model (DEM) for the region at a resolution of $30 \mathrm{~m}$ (Farr et al., 2007), provided elevation for EPIC to calculate atmospheric pressure.

Catchment and Political Boundaries. 10-digit hydrologic units, and county and state boundaries were also used to define HSMUs, which were further linked to surveyed data to prepare EPIC inputs.

By overlaying the above geospatial layers, we obtained a spatial map composed of units with unique properties defined by the following dimensions: unique ID, latitude, longitude, elevation, slope, crop rotation, soil type, county, state, and hydrologic unit.

The geo-location information contained in each HSMU was used to geo-reference climate records and management practices at various scales. First, we used the latitude and longitude of each unit to locate the closest climatological grid of the NLDAS 2, which contains climate forcing data (temperature, precipitation, solar radiation, wind speed, and relative humidity) covering the US at an 8-km resolution. Second, we estimated annual $\mathrm{N}$ and phosphorus fertilizer application rates over 1991 to 2008 based on the state-level statistics from USDA (USDA-ERS, 2013). All counties within a state share the same fertilization levels. The fertilizer application 
rates differentiate between various crop species, but do not address variations for a crop species in different rotations. We derived planting and harvesting dates and heat units required by different crops to reach maturity from typical planting and harvesting dates of major crops in the U.S. provided by USDA (USDA-NASS, 1997) and using the potential heat unit program available at swat.tamu.edu/software/potential-heat-unit-program. We also filled gaps in annual fertilizer databases with the value from the closest year. Finally, at the county level, we derived the fractions of tillage practices compiled by the Conservation Technology Information Center (CTIC, 2008), which were re-processed into three categories: conventional tillage, conservation tillage, and no-till, and gap-filled for 2000-2008 (West et al., 2010). In order to cover the entire simulation period (1991-2008), we assumed that the spatial pattern of tillage practices for the initialization period (1991-1999) was similar to that averaged over 2000-2004. We allocated different tillage practices to each HSMU by assuming that farmers apply no-till and conservation tillage to steep soils in order to preserve soil productivity and protect the environment. Conventional tillage was assigned to flattest HSMUs, while no-till was applied to HSMUs with steepest slopes. The remaining HSMUs implemented conservation tillage.

Each HSMU of the composite layer possessed multi-dimensional information as illustrated in Figure 2. The spatially-explicit scheme employed here allows us to preserve the spatial details of land use and soils patterns, while making it flexible for geo-referencing climate data and crop management practices and aggregating simulation results to the county-scale for comparison.

\subsection{Parallelized EPIC execution and output data analysis}

For the entire US Midwest, executing the over 2 million EPIC runs serially would need 5555.6 hours or 231.5 days. This time consuming task necessitated the development of a parallel computing facility to improve the modeling efficiency. The parallel computing component of the GAMS was constructed by revising and re-structuring modules of software developed by (Nichols et al., 2011; Zhang et al., 2013a). It seamlessly combines Python (python.org), mpi4py (Dalcin et al., 2011) and OpenMPI (www.open-mpi.org) to make use of hundreds of processors simultaneously. The architecture of the parallel computing package was similar to that depicted in Zhang et al., (2013a), except that it executed EPIC instead of the Soil and Water Assessment Tool (SWAT) (Arnold et al., 1998). It first identifies a Master processor among those allocated to a submitted job and splits the entire EPIC runs into a specified number of folders. Next, the 
284 Master processor sends commands to the remaining processors to execute EPIC in each of the 285 folders in parallel. The parallel computing package extracts, organizes, and uploads EPIC simulated agronomic and environmental variables stored in millions of text files into an online PostgreSQL relational database to facilitate data query, analysis, and visualization.

\subsection{Model performance assessment}

In alignment with the previous inventory based cropland C budget estimates by West et al. (2008; 2010), we executed EPIC from 1991 to 2008, with 1991-1999 as a initialization period, and focused on comparing spatial patterns of modeling variables averaged over 2000-2008 at the county scale. We compared our modeling results with two types of data to assess its credibility and identify gaps for further improvements. The first type of data was the county-scale crop yield survey data from USDA-NASS' Quick Stats (quickstats.nass.usda.gov) from 1991 to 2008. The second type of data was derived from an inventory model, which calculates $\mathrm{C}$ in harvested biomass by multiplying NASS county crop yield with a C content factor of 0.45; estimates NPP as a function of $\mathrm{C}$ in harvested biomass, harvest index and root-shoot ratio; and calculates SOC changes by considering organic matter input, tillage, initial SOC concentration, SOC saturation, and the number of years in cultivation.

Two metrics that have been widely used in model assessment (Moriasi et al. 2007) were employed here: percent bias (PBIAS) (Gupta et al., 1999) and Pearson product-moment correlation coefficient $(R)$ (Pearson, 1895). PBIAS is calculated as:

$$
\text { PBIAS }=\left(\frac{\sum_{\mathrm{k}=1}^{\mathrm{T}}\left(\mathrm{f}_{\mathrm{k}}-\mathrm{y}_{\mathrm{k}}\right)}{\sum_{\mathrm{k}=1}^{\mathrm{T}} \mathrm{y}_{\mathrm{k}}}\right) \times 100
$$

where $\mathrm{f}_{\mathrm{k}}$ is the model simulated value at a time unit or location $\mathrm{k}, \mathrm{y}_{\mathrm{k}}$ is the corresponding benchmark data value, and $\mathrm{T}$ represents the total pairs of data. PBIAS measures the average tendency of the simulated data to be larger or smaller than their observed counterparts. Note that, due to cancellation, a result of zero does not necessarily indicate low error (Bennett et al. 2013). 308 Therefore, instead of examining a single aggregated PBIAS, we also derived PBIAS for each location (here at the county scale) and visually presented these values to detect geographic distribution of model performance.

The formula for calculating $R$ is: 


$$
R=\frac{\sum_{\mathrm{k}=1}^{\mathrm{T}}\left(\mathrm{y}_{\mathrm{k}}-\overline{\mathrm{y}}\right)\left(\mathrm{f}_{\mathrm{k}}-\overline{\mathrm{f}}\right)}{\left[\sum_{\mathrm{k}=1}^{\mathrm{T}}\left(\mathrm{y}_{\mathrm{k}}-\overline{\mathrm{y}}\right)^{2}\right]^{0.5}\left[\sum_{\mathrm{k}=1}^{\mathrm{T}}\left(\mathrm{f}_{\mathrm{k}}-\overline{\mathrm{f}}^{2}\right]^{0.5}\right.}
$$

where $\bar{y}$ is the mean of benchmark data for the entire time period or across all sites under evaluation, $\overline{\mathrm{f}}$ is the mean of simulated data. $R$ measures the correlation of the measured and modelled values and indicates how well the model explains the variance in the observations. $R$ ranges between +1 and -1 , with 1 indicating total positive correlation, 0 denoting no correlation, and -1 representing total negative correlation. We calculated $R$ to analyze the performance of GMAS to reproduce spatial patterns of cropland $\mathrm{C}$ budgets averaged over multiple years and at the annual scale. The joint use of PBIAS and $R$ helps depict a fuller picture of the model performance in terms of both relative error and preserving the data pattern (Bennett et al. 2013).

\section{Results and Discussion}

\subsection{Evaluating EPIC simulated cropland carbon budgets against USDA-NASS surveyed crop yield and inventory based $\mathrm{C}$ estimates}

With the inventory estimates of total $\mathrm{C}$ in harvested biomass, we observed concentrated areas of harvested biomass and associated regional $\mathrm{C}$ sinks in the study area (Figure 1 \& Figure $3 \mathrm{a}-\mathrm{b}$ ). GAMS captured this spatial pattern with an $R$ value of 0.89 (Figure 4a). As crop yield represents a significant portion of total biomass production and the crop yield-to-total biomass ratio does not vary much geographically, the spatial distribution of NPP is similar to that of harvested C (Figure 3c-d). Not surprisingly, the inventory estimates and EPIC simulations of NPP agree favorably with each other with a high correlation of 0.90 (Figure 4b), though these two methods derive total biomass production with fundamentally different approaches. Summed over the cropland in the Midwest US, EPIC slightly underestimated total crop yield compared to NASS

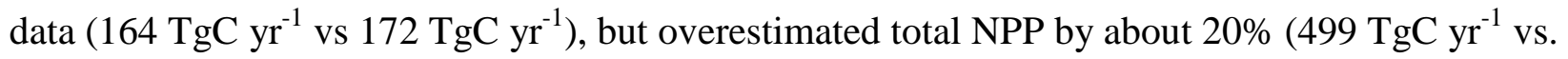

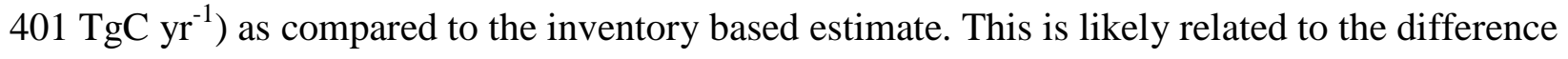
in how harvest index is determined in these two approaches. Although the maximum harvest index in EPIC is the same as those used by West et al., (2008), the actual harvest index used at harvesting is lower, because EPIC considers impacts of environmental stresses, including water and nutrients, and reduces the harvest index accordingly. The smaller harvest index in EPIC resulted in higher estimated NPP, even though EPIC underestimated crop yield. 
The close match regarding crop yield and NPP indicates that these two methods estimated similar amounts of residue inputs into soils, which were calculated as NPP minus harvested C. However, this did not translate into a close correspondence between the simulated SOC change patterns by these two methods (Figure 3e-f; Figure 4c); though they agreed on the total SOC

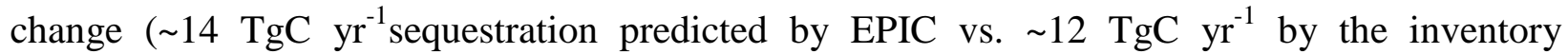
method). A closer look at the spatial distribution of SOC change reveals a wider variability in the EPIC results versus the inventory based estimates. EPIC simulated county-scale SOC change ranges from $\sim-80,614$ to $\sim 270,012 \mathrm{MgC}$ county $^{-1} \mathrm{yr}^{-1}$, which compares to a much narrower range between $\sim-43-\sim 107,292 \mathrm{MgC}$ county $^{-1} \mathrm{yr}^{-1}$ of the inventory method. This contrast is related potentially to the more variable spatial details represented in the EPIC modeling system, which includes finer soils, land use, and climate forcing. For example, EPIC used SSURGO (with a scale 1:24,000) for soil properties, CDL to map crop rotation, and NLDAS climate inputs with a resolution of ca. $8 \mathrm{~km}$, while the inventory method derived SOC change from STATSGO (with a scale 1:250,000) and does not account for climate forcing variability.

Regarding NEE, the relatively smaller magnitude of SOC change as compared with harvested $\mathrm{C}$ rendered the pattern of NEE dominated by the distribution of harvested $\mathrm{C}$ (Figure $3 g-h$ ). Not surprisingly, we achieved a high correlation ( $\mathrm{R}$ of 0.87 ) between the two sets of NEE estimates (Figure 4d). EPIC estimated an annual cropland C flux of -272 $\mathrm{TgC}^{-1}$, which is

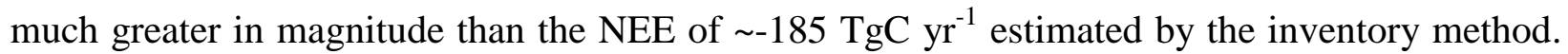
This difference is primarily caused by the discrepancy between NPP estimates, which influences residue inputs into soils and respired $\mathrm{C}$ flux into the atmosphere.

At the annual scale, harvested C, NPP, SOC change, and NEE estimated by EPIC also showed positive correlation with those estimated from the inventory method, but the spatial agreement deteriorated compared to the assessment using data averaged over 2000-2008 (Figure 5). For example, the average annual correlation from 2000 to 2008 is ca. 0.73 for harvested C, lower than the $\mathrm{R}$ value of 0.89 calculated using the multi-year average crop yield data. Generally, EPIC's performance improved over time, with average performance over 2000-2008 better than that over 1991-1999. The relatively poor performance during 1991-1999 may be related to the unstable equilibrium in SOC due to incomplete initialization and the lack of accurate crop 
management data. Notably, the GAMS simulations can be extended beyond 2000-2008 for longterm estimates when climate and crop management data are provided.

371 Overall, the corroboration between the inventory method and GAMS highlights the 372 robustness of GAMS for simulating county-scale cropland $\mathrm{C}$ budgets as influenced by a suite of 373 interacting climatic, edaphic, hydrologic, and anthropogenic factors. Meanwhile, as an 374 independent estimate of cropland $\mathrm{C}$ budgets, the EPIC results also confirmed the reliability of a 375 widely used inventory method (West et al., 2008; West et al., 2010). However, the comparisons 376 also raised the disagreement between EPIC and the inventory method for SOC change and NEE, 377 deserving further analysis.

\section{8}

\subsection{Individual species comparison between EPIC simulated and NASS surveyed crop yields}

The results presented in section 3.1 compared cropland $\mathrm{C}$ budgets aggregated across all crop species in the US Midwest (West et al., 2010). This aggregated assessment provides little information on the performance of EPIC for each crop species. We further examined the performance of EPIC for reproducing spatial patterns of each of the six major crop species, including corn, soybean, winter wheat, spring wheat, alfalfa, and sorghum (Figure 6 and 7). Two types of assessments were conducted: [1] spatial correlation between EPIC simulated and NASS reported crop yield averaged over 2000-2008, and [2] annual spatial correlation over 1991-2008.

Corn and soybean, the two most planted crops in the US Midwest, have higher yield in the central and eastern states than in the northern states of the US Midwest. EPIC preserved this NASS reported pattern (Figure 6a-d). Notably, EPIC tended to substantially under-estimate corn and soybean yield in western Nebraska and Kansas, while exhibiting large positive biases in eastern Kansas, much of Missouri, and part of Indiana. For counties in other states, the yield bias in general fell between $-30 \%$ and $+30 \%$ (Figure 9a-b). When excluding the two heavily irrigated states (i.e. Nebraska and Kansas), we observed a noticeable increase in spatial correlation between EPIC simulated and NASS reported corn and soybean yield. For corn, correlation increased from 0.42 when all states data were used (R_all) to 0.72 when excluding Kansas and Nebraska (R_rainfed) (Figure 8a). Similarly, R_rainfed for soybean (0.78) was much higher than R_all (0.48) (Figure 8b). 
For winter wheat, we observed a poor performance of EPIC for capturing NASS reported spatial yield distribution (Figure 6e-f), with R_all of 0.19 and R_rainfed of 0.42 (Figure 8c). For about half of the counties with winter wheat production, EPIC simulated yield bias was either less than $40 \%$ or over $40 \%$, with the greatest under- and overestimations in Kansas and North Dakota, respectively (Figure 9c).

For alfalfa, EPIC overestimated alfalfa yield averaged over 2000-2008 in northern Wisconsin, southern Illinois, and the southeast of Kansas by 50\%, while under-estimating yield in western Nebraska and Kansas by 40\% (Figure 7a-b; Figure 9d). We also observed significant increase in spatial correlation between EPIC simulated and NASS reported alfalfa yield by excluding Nebraska and Kansas, with R_all of 0.34 and R_rainfed of 0.77 (Figure 8d).

The spatial domains of spring wheat and sorghum are more localized compared with the other four crops; with sorghum mainly presentin Kansas and spring wheat in North Dakota and much of Minnesota (Figure 7c-f). For spring wheat, EPIC captured its spatial yield pattern well with an $R$ value of 0.83 (Figure 8e), the highest among all six crops. The bias of EPIC simulated, spring wheat yield was between $-30 \%$ and $+30 \%$ for most counties, but reached $50 \%$ in eastern North Dakota and several counties in middle Minnesota (Figure 9e). For sorghum, we also observed a close match between the spatial distribution of the EPIC simulated and NASS reported yield as indicated with a $\mathrm{R}$ value of 0.73 (Figure $8 \mathrm{f}$ ), as well as an overestimation of crop yield in most counties (Figure 9f).

For the multi-year average assessment, the crop yields simulated by EPIC explained the dominant spatial pattern at the county scale reported by NASS for all six crops (Figure 7\&8). However, we also observed pronounced overestimation and underestimation in the eastern and western parts of the evaluation domain, respectively (Figure 9). The failure to adequately simulate irrigation management in Nebraska and Kansas significantly compromised the performance of EPIC in these two states. By excluding them, we observed a noticeable increase in spatial correlation (at least 0.23 ) between EPIC simulated and NASS reported crop yield for the four widespread crops (i.e. corn, soybean, winter wheat, and alfalfa) that spanned across both rainfed and irrigated regions. In most counties of the ten states dominated with rainfed cropping systems, we observed either moderate underestimation or overestimation (Figure 9a-d), with 
overestimation as the major pattern for all six crops except sorghum. For some counties, overestimation reached over $50 \%$. An extreme case is spring wheat, for which EPIC overestimated crop yield by $50 \%$ for about half of the counties within the spring wheat domain. The optimistic prediction by EPIC for rainfed regions is possibly caused by the inadequate consideration of the negative effects of pest damage and excess water on crop growth, among other factors.

We also extended the multi-year average assessment of EPIC to an annual scale for the period of 1991-2008 (Figure 10). In general, EPIC performed better in the later years than in the early years of the simulation period for all six crops, highlighting that completeness and accuracy of input data play a crucial role in reliable agroecosystem modeling. This is consistent with previous findings obtained at the site scale that EPIC performed better for sites with complete and detailed agronomic data than for those sites without detailed management information (Zhang et al., 2013b). EPIC's annual performance (Figure 10) is in general comparable to the multi-year average assessment (Figure 8). The average annual spatial correlation over 2000-2008 is close to the spatial correlation calculated with multi-year average crop yield. When excluding Nebraska and Kansas, we also obtained increased spatial correlation similar to that shown in Figure 8 .

\subsection{Assessing accuracy of simulated cropland area used in GAMS simulations}

Accuracy of the geospatial modeling system is heavily dependent on the CDL and SSURGO. When overlaying CDL and SSURGO to define HSMUs, the final cropland area used by EPIC is determined by both the accuracy of CDL and the completeness of soil properties in SSURGO. We found a high correlation between the county-scale cropland area used by EPIC and those from NASS (Figure 11). The US Midwest cropland area simulated by EPIC was about 72 million ha, approximately $6.5 \%$ lower than the NASS surveyed area of 77 million ha. Notably, in the US Midwest, the total alfalfa in NASS is ca. 4.3 million ha, which is much higher than the simulated alfalfa area of only 1.6 million ha. This was mainly caused by the low accuracy of CDL for alfalfa identification (USDA-NASS, 2014), which underestimated alfalfa by 40-50\%. In addition, we discarded numerous small HSMUs that only accounted for about $2 \%$ of the total cropland area, but comprised about 2 million units. These factors, in conjunction with missing complete 
soil parameter sets for EPIC runs on a small portion of the cropland area, resulted in an overall underestimation of cropland area in the US Midwest by 5 million ha. The cropland area underestimation in part explains why we over predicted crop yield per unit area (Figure 7, 8, and 9) but still simulated well total crop yields. With future updates of the SSURGO database and refinement of CDL, we expect to see further improvement in geospatial representations of the agricultural landscapes in the US Midwest.

An individual plant species analysis indicated that simulated cropland area closely matched the corresponding NASS data for corn, soybean, and winter wheat, but alfalfa area was pronouncedly underestimated (Figure 12). Compared to NASS data averaged over 2000-2008, the simulated cropland area across the US Midwest was overestimated by $13 \%$ and $17 \%$, respectively, for corn and soybean, and underestimated by $8.4 \%$ for winter wheat. For alfalfa, our simulated area was about $60 \%$ lower than that reported by NASS. In addition, our modeling system significantly overestimated spring wheat area while underestimating sorghum area. These accuracy metrics are in general poorer than those reported for CDL (USDA-NASS, 2014), which may be caused by the simplification of crop rotations with the aim of reducing the complexity of preparing EPIC required crop management files and the number of HSMUs (Sahajpal et al., 2014). As mentioned above, we identified over 2 million HSMUs for EPIC simulations. Without crop rotation simplification the number of HSMUs would reach over 7 million, greatly increasing the computational cost and data storage burden. Cropland area under corn and soybean increased because they represent dominant crop rotations and certain crop rotation types with small shares were merged into them during the simplification procedure.

For the two locally concentrated crops (spring wheat and sorghum) significant biases in crop area were identified. Simulated spring wheat area was $34 \%$ higher than the NASS reported area, while simulated sorghum area was about $60 \%$ lower. Our rotation simplification scheme expands dominant rotations while diminishing minor ones (Sahajpal et al., 2014). In North Dakota, spring wheat was a dominant crop species that accounts for ca. $34 \%$ of total cropland of 7.8 million ha, but a minor crop species covering only ca. $9 \%$ of the total cropland area (6.4 million ha) in South Dakota. As the simplified crop rotations in South Dakota preserved only 80\% of the accuracy of CDLs, we omitted all the spring wheat in South Dakota (Figure 7i-j). Crop rotations simplification caused shrinkage of sorghum area in Nebraska and South Dakota, because its 
acreage accounted for only $1.9 \%$ and $2.0 \%$ of the total cropland area in Nebraska and South Dakota (Figure 7k-1), respectively, leading to merging of sorghum-involved rotations into other representative ones. Similarly, acreage of sorghum was ca. 1.2 million ha or $13.8 \%$ of the total cropland in Kansas, making it a minor rotation and thus a significant loss of sorghum area.

An annual-scale analysis also showed higher accuracy of simulated crop area for corn, soybean, and winter wheat than for alfalfa, spring wheat, and sorghum (Figure 13). A clear accuracy improvement over time was observed for all crops, as we derived crop rotations using CDLs from 2007 to 2011 and assumed this crop rotation pattern was the same for years before this period. This trend, to some extent, explains the improved performance of EPIC for simulating crop yield over time (Figure 10). Furthermore, these high annual correlation coefficients between simulated and NASS reported cropland area testify to the value of the 497 GAMS for annual scale cropland C flux estimates.

\subsection{Discussion}

Overall, GAMS, as described and tested here, successfully simulated crop yields and cropland $\mathrm{C}$ budgets. The correlation between EPIC and the inventory method was close to 0.9 for harvested C, NPP, and NEE for multi-year average comparison, and was larger than 0.65 at the annual scale. We also identified notable discrepancies between the EPIC simulated crop yields and C fluxes and those either reported by NASS or estimated with a widely used inventory method. Below we elaborate on possible causes of these disagreements and discuss potential opportunities for further improving GAMS to support sustainable $\mathrm{C}$ management.

\subsubsection{Possible explanations for the discrepancies between EPIC simulated and NASS reported crop yields}

For the six crops simulated here, crop yield overestimation was the dominant pattern, except for winter wheat. For corn, soybean, alfalfa, spring wheat, and sorghum, EPIC generally underestimated crop yields in the west while overestimated crop yields in the middle and the east of this region. The underestimation in western Nebraska and Kansas was primarily due to the failure to adequately simulate the effects of irrigation, a key practice boosting crop production in these areas. The lack of spatial representation of species-specific irrigated farms, irrigation schedule, and irrigation volume impeded us from incorporating irrigation into GAMS in a 
consistent way. Irrigation changes plant growth and water availability, which in turn affects plant litter inputs and microbially-mediated SOC decomposition, thereby altering net cropland C flux. Therefore, integrating detection of irrigated areas by remote sensing and locally surveyed, irrigation management information promise to help improve simulations of crop yields and C budgets.

We did not identify any obvious reasons behind EPIC's overestimation of crop yield. A literature review on previous applications of EPIC revealed that EPIC tended to over predict crop yield on rainfed land (Thomson et al., 2005b). Possible explanations are diverse, such as inadequate considerations of pest damage, detrimental effects of excess soil water, and competition between staple crops and weeds, as well as unrealistically optimistic simulation of biophysical parameters (such as leaf area index). Additionally, uncertainties arise from errors in soil data, climate forcing, and management schedule, including inaccurate planting and harvesting dates, extending state-level fertilizer application to each county, approximation of the timing of fertilization and tillage, and idealized allocation of county-scale tillage fractions. All these sources of uncertainties interact with each other and propagate through the processes simulated in EPIC, making it a challenge to identify the mechanisms responsible for EPIC's performance. To address this challenge, new data with refined quality and details (both spatial and temporal) and improved understanding of relevant agroecosystem processes and their robust mathematic representation in models are required. How to characterize and quantify these sources of uncertainties remain a challenge and require further research.

Similar to previous studies, we found that EPIC has difficulties for simulating winter wheat yields (Asseng et al., 2013). In general, winter wheat yield was underestimated in the northern area while overestimated in the southern part of the US Midwest. We derived three major crop rotations containing winter wheat, i.e. corn-soybean-winter wheat in the northern states and winter wheat-fallow and corn-winter wheat in the southern states. Winter wheat distinguishes itself from other annual crops because it is planted in fall and harvested in late spring or early summer of next year. We encountered some difficulties in preparing crop rotation management files that involve winter wheat. The typical planting date is usually earlier than the typical harvesting date of other annual crops such as corn and soybean, while its typical harvesting date is often later than the planting date of other annual crops. We had to shrink the length of growing 
seasons of both winter wheat and other annual crops in rotation by delaying planting and shift harvesting date earlier. This midway solution may deteriorate EPIC's performance for both winter wheat and other annual crops, with greater negative effects on winter wheat simulations because it is always impacted by such a compromise while other annual crops do not suffer when they are not in rotation with winter wheat. In addition, the varying performance of EPIC in Kansas as compared to that in the northern areas for winter wheat might be related to the crop species rotated with winter wheat. In Kansas, winter wheat often alternates with fallow, while in other areas it is usually in rotation with other crops. These factors interact with many other aforementioned uncertainties and require further systematic analysis.

\subsubsection{Mismatch between EPIC simulated and inventory estimated SOC change}

Of the estimated $\sim 5.5-6.0 \mathrm{Pg} \mathrm{CO}_{2}$-eq $\mathrm{yr}^{-1}$ GHG mitigation potential of agricultural technologies and practices at the global scale, approximately $89 \%$ comes from soil C sequestration (Smith et al., 2007). Therefore, diagnosing the discrepancies between EPIC simulated and inventory estimated SOC change is important for improving the understanding of the potential of soils in the US Midwest for GHGs mitigation.

We believe the major cause for the difference between EPIC simulated and inventory estimated SOC change lies in the fundamentally distinct approaches used to calculate SOC dynamics. EPIC explicitly considers microbially mediated, soil organic matter (SOM) dynamics as influenced by an array of biotic and abiotic factors, such as the quantity and quality of the plant litter inputs (e.g. lignin and cellulose content), soil texture, water content, temperature, oxygen availability, and the physical and chemical structure and composition of SOM, among others. In order to adequately simulate these processes, EPIC needs inputs of climate forcing, physical and chemical soil properties, and crop management practices (e.g., fertilizer, tillage, planting, and harvesting). In contrast, the inventory method estimates SOC change by considering its empirical relationship with initial SOC, residue input, tillage practice, length of cultivation, and SOC saturation. These two approaches suffer from different sets of uncertainty factors. EPIC uncertainties arise from errors in climate records, inaccurate soil parameters, incomplete management information, and interactions among these factors. Although the inventory method suffers less from input data and parameter errors, it relates SOC change with several control factors instead of systematically examining SOC dynamics as regulated by the 
575 joint impacts of all controls. This renders it susceptible to uncertainties arising from 576 extrapolating site-scale observations to regional-scale estimates.

577 Another cause of the mismatch is the inaccurate representation of crop rotations in GAMS. As noted in section 3.3, the CDL-derived alfalfa area is substantially underestimated in GAMS; the simplification of crop rotation brought enormous computation benefits but at the cost of the accuracy of different crop species. These misrepresentations of crop species undermine simulated NPP, harvested biomass, and residue input into soils, as well as SOC change. In addition, we did not explicitly consider corn silage and sorghum silage, because CDL does not distinguish between the uses of these two crops for grain and silage. Due to a higher harvest index (more biomass is removed from field) for silage crops, plant residue inputs into soils and SOC sequestration are likely to be discounted. However, this simplified treatment of corn silage and sorghum silage seems to have minimal impacts on simulation results of SOC and NPP, as corn silage and sorghum silage account for only $4.7 \%$ and $2.4 \%$ total corn and sorghum acreage, respectively.

589 Due to the lack of regional scale SOC observations, it is difficult to derive solid conclusions 590 about which method performs better under what conditions. Systematic analysis of the sources of uncertainty for each approach is required to better understand their strength and limitations.

\subsubsection{Potential parameterization strategies to further improve EPIC simulations}

In this modeling exercise, we used priori literature reported parameter values and extensive geospatial data to drive EPIC. This model setup method heavily relies on the quality of input data. In sections 3.4.1 and 3.4.2, we discussed the uncertainties of EPIC simulations related input data. With further improvement in CDL, a more complete SSURGO map and soil properties database, and improved crop management survey data, the reliability of EPIC simulations is expected to be further enhanced. For example, by including more rotations into agricultural landscapes, the accuracy of the crop rotation map can be further improved (Sahajpal et al., 2014). However, this benefit comes at a significant cost of computational resources.

Another popular parameterization strategy consists of identifying the most uncertain parameters and adjusting them within prescribed ranges to minimize the difference between simulated and observed variables of interest. However, information contents contained in 
observed variables may not be adequate for characterizing complex hydrologic, biophysical, and biogeochemical processes (Jakeman and Hornberger, 1993). Using crop yields alone to calibrate EPIC may result in parameter overfitting. That is, parameters may be adjusted to compensate for errors associated with input data, model structure, and observations against which a model is calibrated (Jakeman et al., 2006; Zhang et al., 2009). In addition, this strategy often requires running models repeatedly, demanding many more computational resources than the first strategy. Given the limited availability of computing time and data storage capacity, we did not perform extensive parameter calibration in this exercise. Note that uncertainty identification and characterization of input data and model parameters are important, and have the potential to help quantitatively assess errors associated with prediction of $\mathrm{C}$ budget components, which are critical for minimizing risks of $\mathrm{C}$ related management arrangements and policy making (Post et al., 2008a; Post et al., 2008b; Updegraff et al., 2010; Varella et al., 2010).

616

\subsubsection{Flexibility of the geospatial modeling framework}

As shown in Figure 2, GAMS encompasses three loosely connected components, each of which can be adapted for other models and analyses. For example, with minor/moderate revisions, the GIS analysis and parallel computing functions can be applied to geospatial data at a global scale or other biophysical and biogeochemical models. If the historical climate databases are replaced with future climate predictions, GAMS can be applied to simulate and understand climate change impacts on agroecosystem productivity (Izaurralde et al., 2003; Thomson et al., 2005a). The composite geospatial layer used to define HSMUs for EPIC simulations contains multi-dimensional information, allowing the integration of the model results with hydrologic and social-economic models to explore the broader impacts of shifts in agricultural management practices. For example, the hydrologic layer embedded in HSMUs enables the joint use of EPIC land simulations with aquatic processes simulated in watershed models, such as SWAT, to understand water quality consequences of upland soil management.

The geo-location information contained in the composite HSMU layer also allows the spatially modeling results to be aggregated to coarser scales (e.g. low vs. high productive lands within a county, hydrologic unit, or state) that are commensurate with economic and policy analysis models. For example, EPIC simulations at a multi-county scale have been fed into a regionally focused Global Climate Assessment Model (GCAM) for understanding future 
agricultural land use changes under alternative $\mathrm{C}$ prices and radiative forcing levels (Thomson $e t$ al., 2013). EPIC simulations were also grouped by differentiating less productive and fertile lands within a 10-digit hydrologic unit and used to explore availability of alternative bioenergy crops under various biomass prices and associated environmental consequences (EgbendeweMondzozo et al., 2011; Egbendewe-Mondzozo et al., 2013; Gelfand et al. 2013). GAMS provides detailed spatial results for the historical baseline scenario that are critical for robust estimation of benefits and costs of alternative land use scenarios. The flexibility of the geospatial modeling framework makes it easy to provide the inputs required by those socio-economic models and provides opportunities for understanding potential uncertainty arising from aggregating spatial variability.

\section{Conclusions}

This study introduces a novel geospatial agricultural modeling system, or GAMS, integrating a mechanistic model (in this case EPIC), spatially-resolved data, surveyed management data, and supercomputing functions. Importantly, GAMS was designed to be highly modularized and thus flexible, rendering it straightforward to update input data with emerging observations; replace EPIC with other models; and integrate its simulation results with socio-economic and watershed models - thus making it cost-effective to maintain and adapt GAMS for diverse application purposes.

The overall agreement between the GAMS simulated and inventory estimated cropland county-scale $\mathrm{C}$ budgets provided independent confirmation of the credibility of both methods. However, we also detected notable differences in the magnitude of NPP and NEE, as well as in the spatial pattern of SOC change. With individual plant species analyses and annual-scale comparisons, we explored potential causes of the discrepancies by analyzing the differences between EPIC and the inventory method in data requirements, representation of agroecosystem processes, completeness and accuracy of crop management data, and accuracy of spatial crop area representation. Based on these analyses, we discussed strategies to further improve GAMS' performance by updating input data (such as land use, soil, and irrigation) and by designing more efficient parallel computing capability that allows for a systematic examination of uncertainty 
2

3 8

\section{Acknowledgements}

666 We sincerely appreciate the valuable comments provided by the three anonymous reviewers, 667 which have greatly improved the quality of this manuscript. This work was partially funded by 668 the DOE Great Lakes Bioenergy Research Center (DOE BER Office of Science DE-FC02669 07ER64494, DOE BER Office of Science KP1601050, DOE EERE OBP 20469-19145), and 670 NASA as part of the North American Carbon Program (NNH12AU03I) and the New 671 Investigator Program (NIP) (NNH13ZDA001N). The views expressed here are those of the 672 authors and do not necessarily represent the views or policies of the U.S. Environmental 673 Protection Agency. 


\section{References}

Apezteguía, H.P., Izaurralde, R.C., Sereno, R., 2009. Simulation study of soil organic matter dynamics as affected by land use and agricultural practices in semiarid Córdoba, Argentina. Soil and Tillage Research 102, 101-108.

Arnold, J.G., Srinivasan, R., Muttiah, R.S., Williams, J.R., 1998. Large area hydrologic modeling and assessment part I: Model development1. JAWRA Journal of the American Water Resources Association 34, 73-89.

Asseng, S., Ewert, F., Rosenzweig, C., Jones, J., Hatfield, J., Ruane, A., Boote, K., Thorburn, P., Rötter, R., Cammarano, D., 2013. Uncertainty in simulating wheat yields under climate change. Nature Climate Change 3, 827-832.

Bennett, Neil D., Barry FW Croke, Giorgio Guariso, Joseph HA Guillaume, Serena H. Hamilton, Anthony J. Jakeman, Stefano Marsili-Libelli et al. "Characterising performance of environmental models." Environmental Modelling \& Software 40 (2013): 1-20.

Causarano, H.J., Doraiswamy, P.C., McCarty, G.W., Hatfield, J.L., Milak, S., Stern, A., 2008. EPIC modeling of soil organic carbon sequestration in croplands of Iowa. Journal of environmental quality $37,1345-1353$.

Causarano, H.J., Shaw, J.N., Franzluebbers, A.J., Reeves, D.W., Raper, R.L., Balkcom, K.S., Norfleet, M.L., Izaurralde, R.C., 2007. Simulating field-scale soil organic carbon dynamics using EPIC. Soil Science Society of America Journal 71, 1174-1185.

Chapin III, F., Woodwell, G., Randerson, J.T., Rastetter, E.B., Lovett, G., Baldocchi, D.D., Clark, D., Harmon, M.E., Schimel, D.S., Valentini, R., 2006. Reconciling carbon-cycle concepts, terminology, and methods. Ecosystems 9, 1041-1050.

CTIC, 2008. Crop residue management survey. Conservation Technology Information Center, West Lafayette, Indiana, USA., http://www.ctic.org/resourcedisplay/255/.

Dalcin, L.D., Paz, R.R., Kler, P.A., Cosimo, A., 2011. Parallel distributed computing using python. Advances in Water Resources 34, 1124-1139.

Egbendewe-Mondzozo, A., Swinton, S.M., Izaurralde, C.R., Manowitz, D.H., Zhang, X., 2011. Biomass supply from alternative cellulosic crops and crop residues: A spatially explicit bioeconomic modeling approach. Biomass and Bioenergy 35, 4636-4647.

Egbendewe-Mondzozo, A., Swinton, S.M., Izaurralde, R.C., Manowitz, D.H., Zhang, X., 2013. Maintaining environmental quality while expanding biomass production: Sub-regional US policy simulations. Energy Policy.

EISA, 2007. Energy independence and security act of 2007. Public Law, http://www.gpo.gov/fdsys/pkg/PLAW-110publ140/pdf/PLAW-110publ140.pdf.

Farr, T.G., Rosen, P.A., Caro, E., Crippen, R., Duren, R., Hensley, S., Kobrick, M., Paller, M., Rodriguez, E., Roth, L., 2007. The shuttle radar topography mission. Reviews of geophysics 45.

Gelfand, Ilya, Ritvik Sahajpal, Xuesong Zhang, R. César Izaurralde, Katherine L. Gross, and G. Philip Robertson. "Sustainable bioenergy production from marginal lands in the US Midwest." Nature 493, no. 7433 (2013): 514-517.

Gupta, H.V., Sorooshian, S., Yapo, P.O., 1999. Status of automatic calibration for hydrologic models: Comparison with multilevel expert calibration. Journal of Hydrologic Engineering 4, 135-143.

Hayes, D.J., Turner, D.P., Stinson, G., McGuire, A.D., Wei, Y., West, T.O., Heath, L.S., Jong, B., McConkey, B.G., Birdsey, R.A., 2012. Reconciling estimates of the contemporary North 
American carbon balance among terrestrial biosphere models, atmospheric inversions, and a new approach for estimating net ecosystem exchange from inventory $\square$ based data. Global Change Biology 18, 1282-1299.

He, X., Izaurralde, R., Vanotti, M.B., Williams, J.R., Thomson, A.M., 2006. Simulating longterm and residual effects of nitrogen fertilization on corn yields, soil carbon sequestration, and soil nitrogen dynamics. Journal of environmental quality 35, 1608-1619.

Huntzinger, D., Post, W.M., Wei, Y., Michalak, A., West, T.O., Jacobson, A., Baker, I., Chen, J.M., Davis, K., Hayes, D., 2012. North American Carbon Program (NACP) regional interim synthesis: Terrestrial biospheric model intercomparison. Ecological Modelling 232, 144-157.

Izaurralde, R., Williams, J.R., McGill, W.B., Rosenberg, N.J., Jakas, M., 2006. Simulating soil C dynamics with EPIC: Model description and testing against long-term data. Ecological Modelling 192, 362-384.

Izaurralde, R., Williams, J.R., Post, W.M., Thomson, A.M., McGill, W.B., Owens, L., Lal, R., 2007. Long-term modeling of soil $\mathrm{C}$ erosion and sequestration at the small watershed scale. Climatic Change 80, 73-90.

Izaurralde, R.C., Rosenberg, N.J., Brown, R.A., Thomson, A.M., 2003. Integrated assessment of Hadley Center (HadCM2) climate-change impacts on agricultural productivity and irrigation water supply in the conterminous United States: Part II. Regional agricultural production in 2030 and 2095. Agricultural and Forest Meteorology 117, 97-122.

Jakeman, A., Hornberger, G., 1993. How much complexity is warranted in a rainfall $\square$ runoff model? Water Resources Research 29, 2637-2649.

Jakeman, Anthony J., Rebecca A. Letcher, and John P. Norton. "Ten iterative steps in development and evaluation of environmental models." Environmental Modelling \& Software 21, no. 5 (2006): 602-614.

Johnson, D., Mueller, R., 2010. The 2009 Crop Data Layer. Photogrammetric Engineering \& Remote Sensing 76, 1201-1205.

Jones, C., Dyke, P., Williams, J., Kiniry, J., Benson, V., Griggs, R., 1991. EPIC: an operational model for evaluation of agricultural sustainability. Agricultural Systems 37, 341-350.

Lal, R., Bruce, J., 1999. The potential of world cropland soils to sequester C and mitigate the greenhouse effect. Environmental Science \& Policy 2, 177-185.

Liang, Xin-Zhong, Min Xu, Xing Yuan, Tiejun Ling, Hyun I. Choi, Feng Zhang, Ligang Chen et al. "Regional climate-weather research and forecasting model."Bulletin of the American Meteorological Society 93, no. 9 (2012): 1363-1387.

Liu, J., 2009. A GIS-based tool for modelling large-scale crop-water relations. Environmental Modelling \& Software 24, 411-422.

Moureaux, C., Debacq, A., Hoyaux, J., Suleau, M., Tourneur, D., Vancutsem, F., Bodson, B., Aubinet, M., 2008. Carbon balance assessment of a Belgian winter wheat crop (Triticum aestivum L.). Global Change Biology 14, 1353-1366.

Moriasi, D. N., J. G. Arnold, M. W. Van Liew, R. L. Bingner, R. D. Harmel, and T. L. Veith. "Model evaluation guidelines for systematic quantification of accuracy in watershed simulations." Trans. ASABE 50, no. 3 (2007): 885-900.

Nichols, J., Kang, S., Post, W., Wang, D., Bandaru, V., Manowitz, D., Zhang, X., Izaurralde, R., 2011. HPC-EPIC for high resolution simulations of environmental and sustainability assessment. Computers and Electronics in Agriculture 79, 112-115.

NRC, 2011. Renewable Fuel Standard: Potential Economic and Environmental Effects of US Biofuel Policy. National Academies Press. 
Ogle, S., Davis, K., 2006. Science plan: Mid-continent intensive campaign of the North American Carbon Program: North American Carbon Program, 11 p.

Ogle, S.M., BREIDT, F., Easter, M., Williams, S., Killian, K., Paustian, K., 2010. Scale and uncertainty in modeled soil organic carbon stock changes for US croplands using a process $\square$ based model. Global Change Biology 16, 810-822.

Parton, W.J., Schimel, D., Ojima, D., Cole, C.V., Bryant, R., Arnold, R., 1994. A general model for soil organic matter dynamics: sensitivity to litter chemistry, texture and management. Quantitative modeling of soil forming processes: proceedings of a symposium sponsored by Divisions S-5 and S-9 of the Soil Science Society of America in Minneapolis, Minnesota, USA, 2 Nov. 1992. Soil Science Society of America Inc., pp. 147-167.

Paustian, K., Antle, J.M., Sheehan, J., Paul, E.A., 2006. Agriculture's role in greenhouse gas mitigation.

Pearson, K., 1895. Note on regression and inheritance in the case of two parents. Proceedings of the Royal Society of London 58, 240-242.

Post, J., Conradt, T., Suckow, F., Krysanova, V., Wechsung, F., Hattermann, F.F., 2008a. Integrated assessment of cropland soil carbon sensitivity to recent and future climate in the Elbe River basin. Hydrological sciences journal 53, 1043-1058.

Post, J., Hattermann, F.F., Krysanova, V., Suckow, F., 2008b. Parameter and input data uncertainty estimation for the assessment of long-term soil organic carbon dynamics. Environmental Modelling \& Software 23, 125-138.

Post, W.M., Izaurralde, R.C., Mann, L.K., Bliss, N., 2001. Monitoring and verifying changes of organic carbon in soil. Storing Carbon in Agricultural Soils: A Multi-Purpose Environmental Strategy. Springer, pp. 73-99.

Rao, M.N., Waits, D.A., Neilsen, M.L., 2000. A GIS-based modeling approach for implementation of sustainable farm management practices. Environmental Modelling \& Software 15, 745-753.

Saby, N., Bellamy, P.H., Morvan, X., Arrouays, D., Jones, R.J., Verheijen, F.G., Kibblewhite, M.G., Verdoodt, A., ÜVEGES, J.B., FREUDENSCHUß, A., 2008. Will European soil $\square$ monitoring networks be able to detect changes in topsoil organic carbon content? Global Change Biology 14, 2432-2442.

Sahajpal, R., Zhang, X., Gelfand, I., Izaurralde, C.R., Hurtt, G., 2014. Modeling representative crop rotaions in the Central United States. Computers and Electronics in Agriculture (In Review).

Schaldach, R., Alcamo, J., 2006. Coupled simulation of regional land use change and soil carbon sequestration: A case study for the state of Hesse in Germany. Environmental Modelling \& Software 21, 1430-1446.

Schuh, A.E., Lauvaux, T., West, T.O., Denning, A.S., Davis, K.J., Miles, N., Richardson, S., Uliasz, M., Lokupitiya, E., Cooley, D., 2013. Evaluating atmospheric CO2 inversions at multiple scales over a highly inventoried agricultural landscape. Global change biology 19, 1424-1439.

Schwalm, C.R., Williams, C.A., Schaefer, K., Anderson, R., Arain, M.A., Baker, I., Barr, A., Black, T.A., Chen, G., Chen, J.M., 2010. A model $\square$ data intercomparison of CO2 exchange across North America: Results from the North American Carbon Program site synthesis. Journal of Geophysical Research: Biogeosciences (2005-2012) 115.

Smith, P., Davies, C.A., Ogle, S., Zanchi, G., Bellarby, J., Bird, N., Boddey, R.M., McNamara, N.P., Powlson, D., Cowie, A., 2012. Towards an integrated global framework to assess the 
impacts of land use and management change on soil carbon: current capability and future vision. Global Change Biology 18, 2089-2101.

Smith, P., Martino, D., Cai, Z., Gwary, D., Janzen, H., Kumar, P., McCarl, B., Ogle, S., O’Mara, F., Rice, C., Scholes, B., Sirotenko, O., 2007. Agriculture. In: B. Metz, O.R.D., P.R. Bosch, R. Dave, L.A. Meyer (Ed.), Climate Change 2007: Mitigation. Contribution of Working Group III to the Fourth Assessment Report of the Intergovernmental Panel on Climate Change, Cambridge, United Kingdom and New York, NY, USA.

Srinivasan, R., Zhang, X., Arnold, J., 2010. SWAT ungauged: hydrological budget and crop yield predictions in the Upper Mississippi River Basin. Transactions of the ASABE 53, 1533-1546.

Sus, O., Williams, M., Bernhofer, C., Béziat, P., Buchmann, N., Ceschia, E., Doherty, R., Eugster, W., Grünwald, T., Kutsch, W., 2010. A linked carbon cycle and crop developmental model: Description and evaluation against measurements of carbon fluxes and carbon stocks at several European agricultural sites. Agriculture, ecosystems \& environment 139, 402-418. Thomson, A., Kyle, G., Zhang, X., Bandaru, V., West, T., Wise, M., Izaurralde, R., Calvin, K., 2013. The contribution of future agricultural trends in the US Midwest to global climate change mitigation. Global Environmental Change.

Thomson, A., Rosenberg, N., Izaurralde, R., Brown, R., 2005a. Climate change impacts for the conterminous USA: an integrated assessment: Part 5. Irrigated agriculture and national grain crop production. Climatic Change 69, 89-105.

Thomson, A.M., Brown, R.A., Rosenberg, N.J., Izaurralde, R.C., Benson, V., 2005b. Climate Change Impacts for the Conterminous USA: An Integrated Assessment, Part 3, Dryland Production of Grain and Forage Crops. Climatic Change 69, 43-65.

UNEP, 2013. The Emissions Gap Report 2013: A UNEP Synthesis Report. http://www.unep.org/pdf/UNEPEmissionsGapReport2013.pdf.

Updegraff, K., Zimmerman, P.R., Kozak, P., Chen, D.-G., Price, M., 2010. Estimating the uncertainty of modeled carbon sequestration: The GreenCert ${ }^{\mathrm{TM}}$ system. Environmental Modelling \& Software 25, 1565-1572.

USDA-ERS, 2010. USDA agricultural projections to 2019. http://www.ers.usda.gov/publications/oce-usda-agricultural-projections/oce-20101.aspx\#.Uy4Vg_IdVEA, p. 106.

USDA-ERS, 2013. Fertilizer Use and Price. http://www.ers.usda.gov/data-products/fertilizer-useand-price.aspx\#.UmluAvmkqpA.

USDA-FSA, 2008. Fact sheet: Conservation Reserve Program (CRP) benefits: water quality, soil productivity and wildlife estimates. https://www.fsa.usda.gov/Internet/FSA_File/crpbennies.pdf.

USDA-FSA, 2010. Conservation Reserve Program ANNUAL SUMMARY AND ENROLLMENT STATISTICS FY 2010. http://www.fsa.usda.gov/Internet/FSA_File/annual2010summary.pdf.

USDA-NASS, 1997. Usual Planting and Harvesting Dates for U.S. Field Crops. http://www.nass.usda.gov/Publications/Usual_Planting_and_Harvesting_Dates/uph97.pdf.

USDA-NASS, 2011. Quick Stats 1.0. http://www.nass.usda.gov/Quick_Stats/.

USDA-NASS, 2014. CropScape General Information. http://www.nass.usda.gov/research/Cropland/sarsfaqs2.htm\#Section1_12.0.

USDA-NRCS, 1995. Soil Survey Geographic (SSURGO) Data Base Data Use Information. $\mathrm{ftp}: / / \mathrm{ftp}$. igsb.uiowa.edu/gis_library/Support_Data/Soils/SSURGO.PDF. 
USGCRP, 2012. THE NATIONAL GLOBAL CHANGE RESEARCH PLAN: 2012-2021. http://library.globalchange.gov/u-s-global-change-research-program-strategic-plan-2012-2021.

Varella, H., Guérif, M., Buis, S., 2010. Global sensitivity analysis measures the quality of parameter estimation: the case of soil parameters and a crop model. Environmental Modelling \& Software 25, 310-319.

Wang, J., Chen, J., Ju, W., Li, M., 2010. IA-SDSS: A GIS-based land use decision support system with consideration of carbon sequestration. Environmental Modelling \& Software 25, 539-553.

Wang, X., He, X., Williams, J., Izaurralde, R., Atwood, J., 2005. Sensitivity and uncertainty analyses of crop yields and soil organic carbon simulated with EPIC. TRANSACTIONSAMERICAN SOCIETY OF AGRICULTURAL ENGINEERS 48, 1041.

Wang, X., Williams, J.R., Gassman, P.W., Baffaut, C., Izaurralde, R.C., Jeong, J., Kiniry, J.R., 2012. The EPIC and APEX models: Use, calibration and validation. Trans. ASABE 55, 1447-1462.

West, T.O., Bandaru, V., Brandt, C.C., Schuh, A., Ogle, S., 2011. Regional uptake and release of crop carbon in the United States. Biogeosciences Discussions 8.

West, T.O., Brandt, C.C., Baskaran, L.M., Hellwinckel, C.M., Mueller, R., Bernacchi, C.J., Bandaru, V., Yang, B., Wilson, B.S., Marland, G., 2010. Cropland carbon fluxes in the United States: increasing geospatial resolution of inventory-based carbon accounting. Ecological Applications 20, 1074-1086.

West, T.O., Brandt, C.C., Wilson, B.S., Hellwinckel, C.M., Tyler, D.D., Marland, G., De La Torre Ugarte, D.G., Larson, J.A., Nelson, R.G., 2008. Estimating regional changes in soil carbon with high spatial resolution. Soil Science Society of America Journal 72, 285-294.

Whittaker, C., McManus, M.C., Smith, P., 2013. A comparison of carbon accounting tools for arable crops in the United Kingdom. Environmental Modelling \& Software 46, 228-239.

Williams, J., Jones, C., Kiniry, J., Spanel, D.A., 1989. The EPIC crop growth model. Transactions of the ASAE (USA).

Williams, J.R., Singh, V., 1995. The EPIC model. Computer models of watershed hydrology., 909-1000.

Zhang, X., Beeson, P., Link, R., Manowitz, D., Izaurralde, R.C., Sadeghi, A., Thomson, A.M., Sahajpal, R., Srinivasan, R., Arnold, J.G., 2013a. Efficient multi-objective calibration of a computationally intensive hydrologic model with parallel computing software in Python. Environmental Modelling \& Software.

Zhang, X., Izaurralde, R.C., Arnold, J.G., Williams, J.R., Srinivasan, R., 2013b. Modifying the Soil and Water Assessment Tool to simulate cropland carbon flux: Model development and initial evaluation. Science of the Total Environment 463, 810-822.

Zhang, X., Izaurralde, R.C., Manowitz, D., West, T., Post, W., Thomson, A.M., Bandaru, V.P., Nichols, J., Williams, J., 2010. An integrative modeling framework to evaluate the productivity and sustainability of biofuel crop production systems. GCB Bioenergy 2, 258277.

Zhang, Xuesong, Raghavan Srinivasan, and David Bosch. "Calibration and uncertainty analysis of the SWAT model using Genetic Algorithms and Bayesian Model Averaging." Journal of Hydrology 374, no. 3 (2009): 307-317.

Zhang, X., Sahajpal, R., Manowitz, D.H., Zhao, K., LeDuc, S.D., Xu, M., Xiong, W., Zhang, A., Izaurralde, R.C., Thomson, A.M., 2014. Multi-scale geospatial agroecosystem modeling: A 
2

3

4901 case study on the influence of soil data resolution on carbon budget estimates. Science of The 902 Total Environment 479, 138-150.
7903

8

9

10

11

12

13

14

15

16

17

18

19

20

21

22

23

24

25

26

27

28

29

30

31

32

33

34

35

36

37

38

39

40

41

42

43

44

45

46

47

48

49

50

51

52

53

54

55

56

57

58

59

60

61

62

63

64

65 


\section{List of Figures}

Figure 1. Location of the study area. (The 12 states in the US Midwest show a high overlap with the Corn Belt. The extent of the Corn Belt is adapted from Liang et al. (2011).)

Figure 2. Conceptual diagram of the geospatial modeling framework. (It contains a GIS system fusing multi-source data, a Python based parallel computing package, and relational database query and visualization functions.)

Figure 3. Multi-year average (2000-2008) spatial comparison between EPIC simulated and inventory estimated cropland carbon budget components. (Left panel presents results from the inventory method by West et al. (2010); Right panel includes EPIC simulated variables).

Figure 4. Spatial correlation between EPIC simulated and inventory estimated multi-year average (2000-2008) cropland carbon budget components.

Figure 5. Time series of annual spatial correlation between EPIC simulated and inventory estimated cropland carbon budget components over 1991-2008.

Figure 6. Spatial distribution of species-specific crop yield averaged over 2000-2008 for corn (ab), soybean (c-d), and winter wheat (e-f). (GAMS overestimates winter wheat's extent in Iowa and Minnesota, and northern Wisconsin. In contrast, the crop rotation map used in GAMS leaves out winter wheat in Nebraska and Missouri. This is because we simplified crop rotations derived from multi-year CDLs, which merges crop rotations with minor areas into dominant ones. The winter wheat area in these two states represents less than $8 \%$ of the total cropland area, leading to its omission.)

Figure 7. Spatial distribution of species-specific crop yield averaged over 2000-2008 for alfalfa (g-h), spring wheat (i-j), and sorghum (k-1). (The NASS started to report alfalfa yield and area data in 2009 for Missouri, Indiana, and Ohio; therefore ( $\mathrm{g}$ ) does not show the presence of alfalfa in these states; The underestimation of spring wheat in South Dakota is because it is a minor crop and was removed during the process of simplifying crop rotation; similarly the missing extent of sorghum in South Dakota and Nebraska is also due to the crop rotation simplification that results in the loss of crops with small area.)

Figure 8. Spatial correlation between EPIC simulated and NASS reported multi-year average (2000-2008) species-specific crop yield. (R_all is calculated with data from all counties, while R_rainfed is derived from counties other than Kansas and Nebraska).

Figure 9. Spatial distribution of species-specific bias in EPIC simulated multi-year average (2000-2008) crop yield. (Only those counties with concurrent EPIC simulated and NASS reported data are shown.)

Figure 10. Time series of annual spatial correlation between EPIC simulated and NASS reported species-specific crop yield over 1991-2008.

Figure 11. Spatial correlation between simulated and NASS reported multi-year average (20002008) total cropland area. 
4941 Figure12. Spatial correlation between simulated and NASS reported multi-year average (2000$6942 \quad$ 2008) species-specific cropland area.

8943 Figure 13. Time series of annual spatial correlation between simulated and NASS reported $9944 \quad$ species-specific cropland area over 1991-2008. 


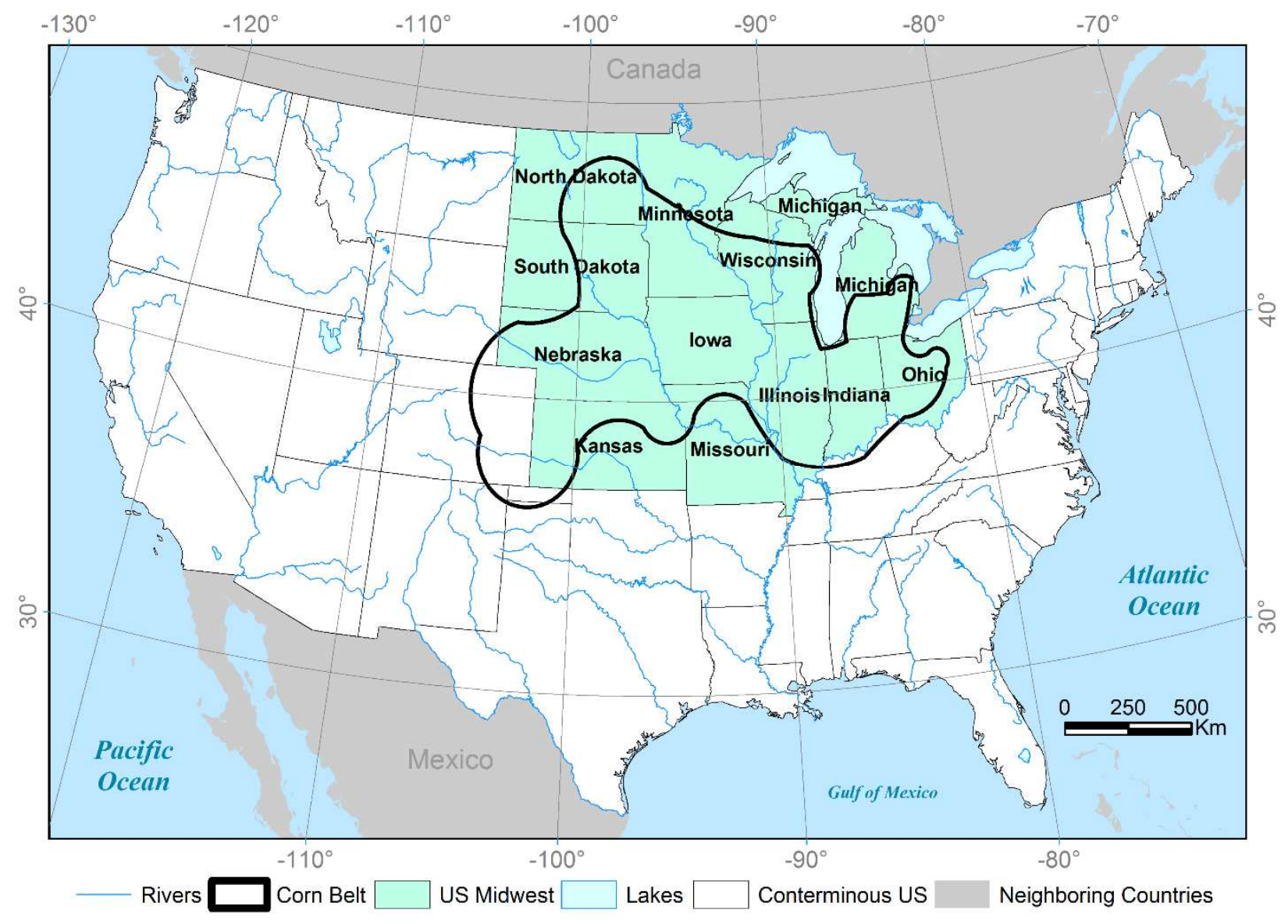

947 Figure 1. Location of the study area. (The 12 states in the US Midwest show a high overlap with 948 the Corn Belt. The extent of the Corn Belt is adapted from Liang et al. (2011).) 


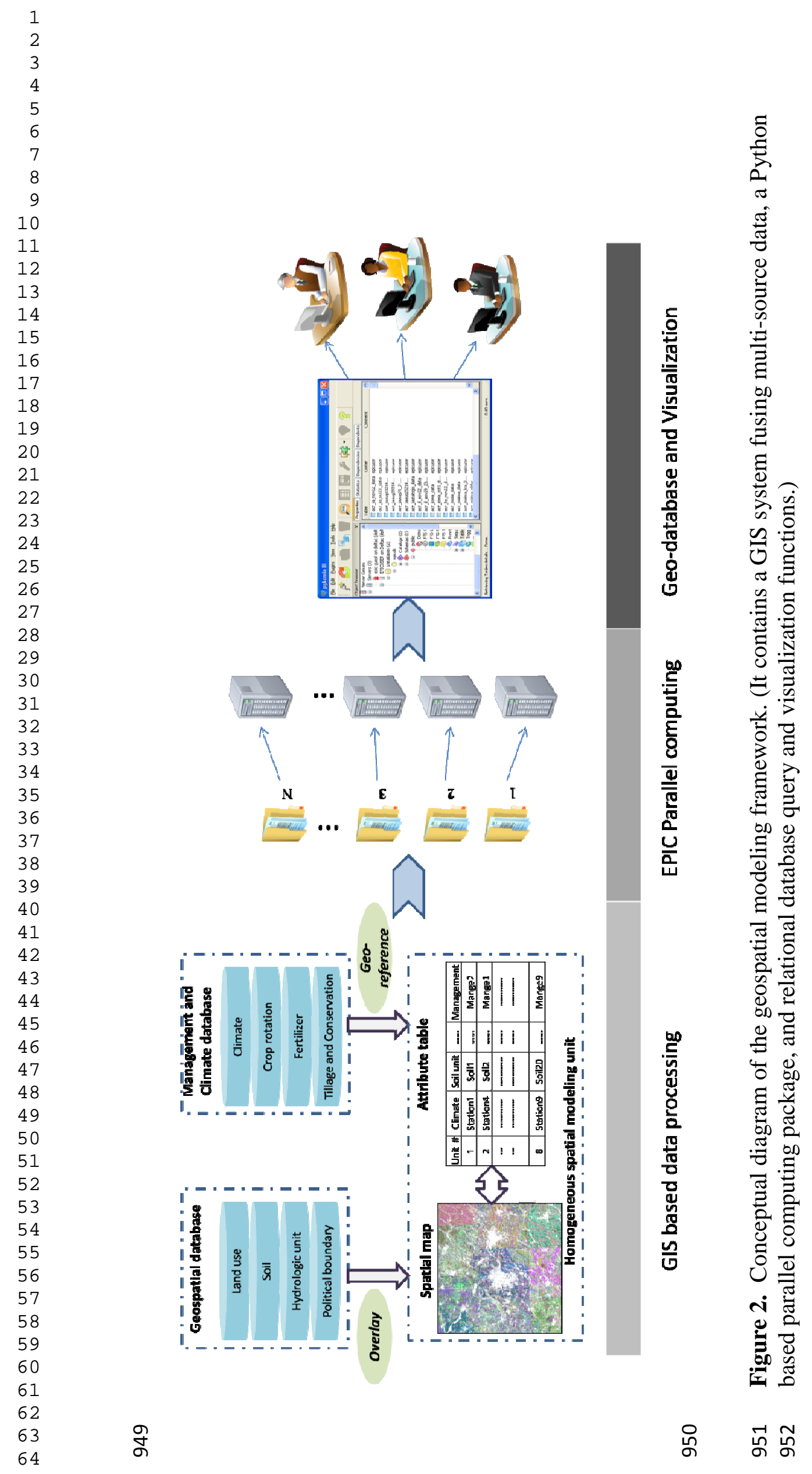



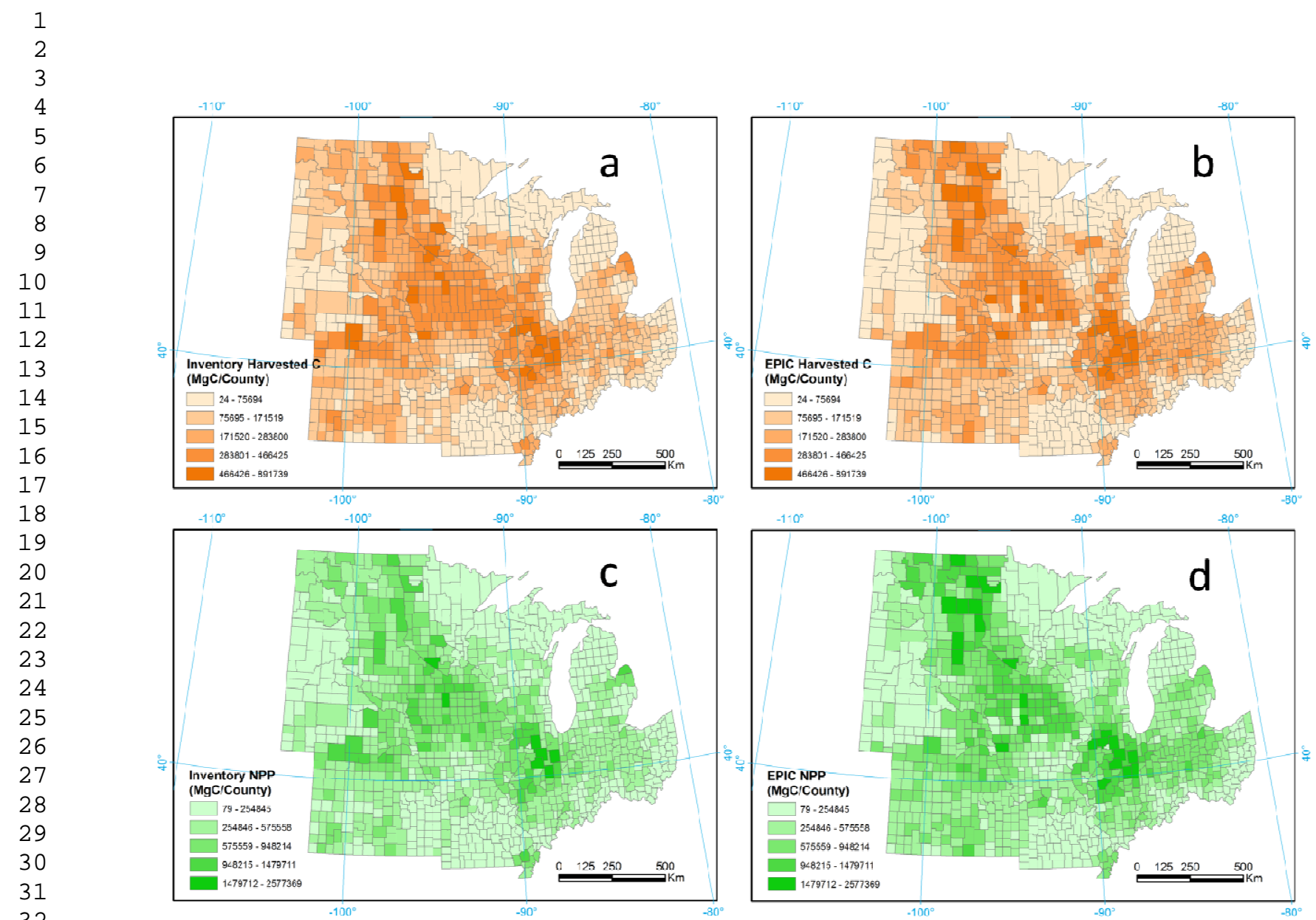

33
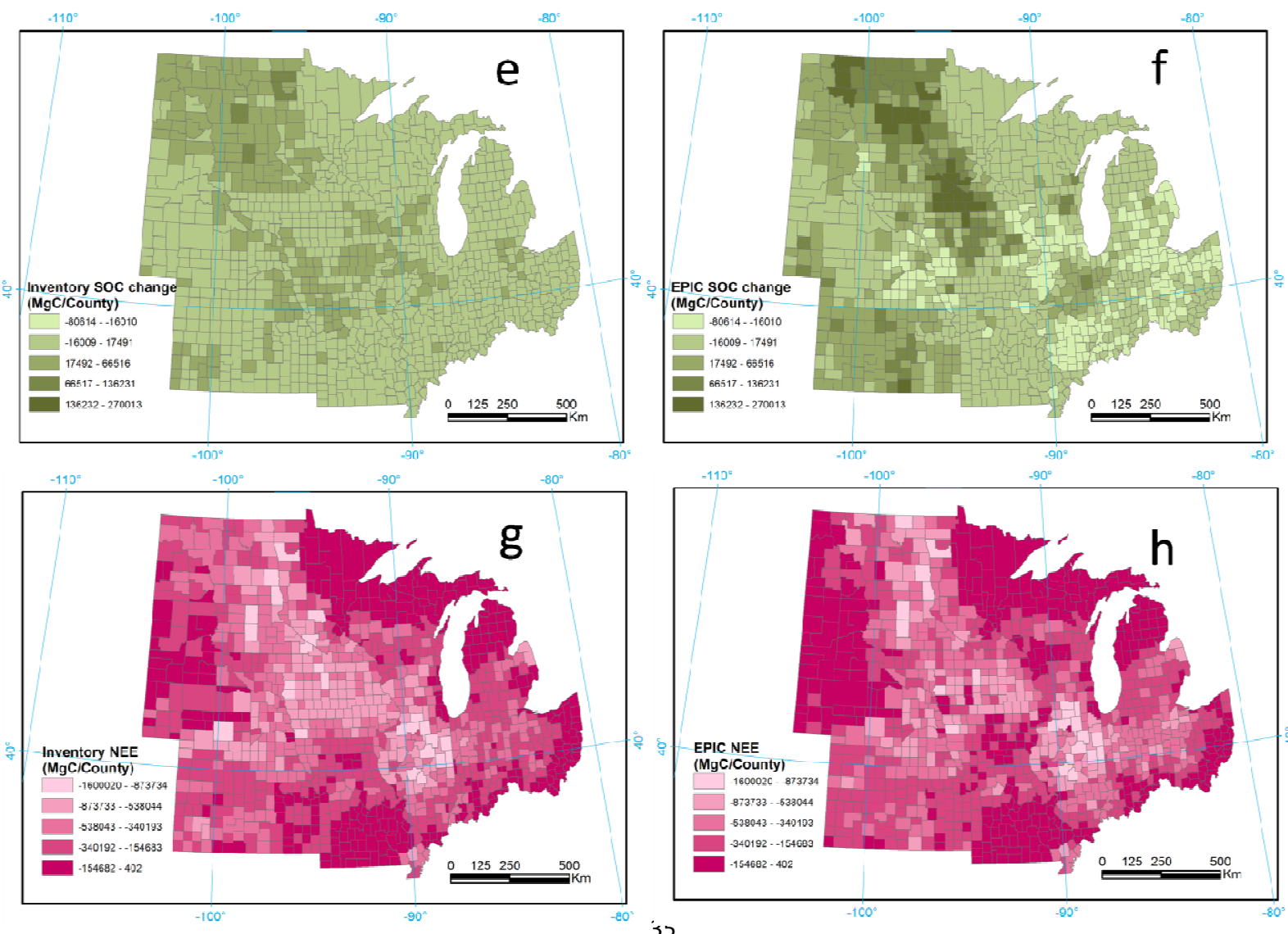
4954 Figure 3. Multi-year average (2000-2008) spatial comparison between EPIC simulated and 6955 inventory estimated cropland carbon budget components. (Left panel presents results from the 7956 inventory method by West et al. (2010); Right panel includes EPIC simulated variables). 

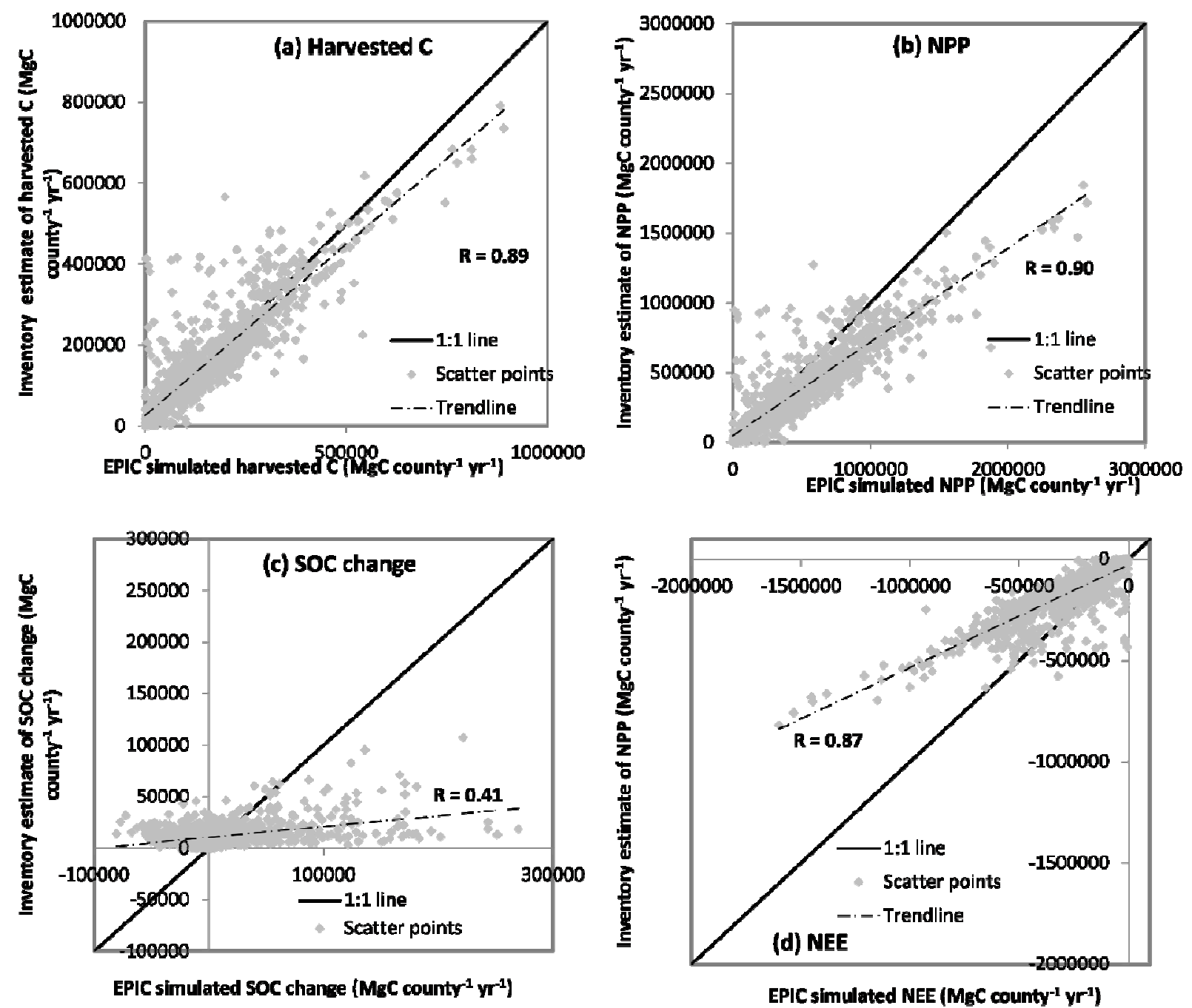

EPIC simulated NEE (MgC county-1 $\mathbf{y r}^{-1}$ )

958 Figure 4. Spatial correlation between EPIC simulated and inventory estimated multi-year 959 average (2000-2008) cropland carbon budget components. 

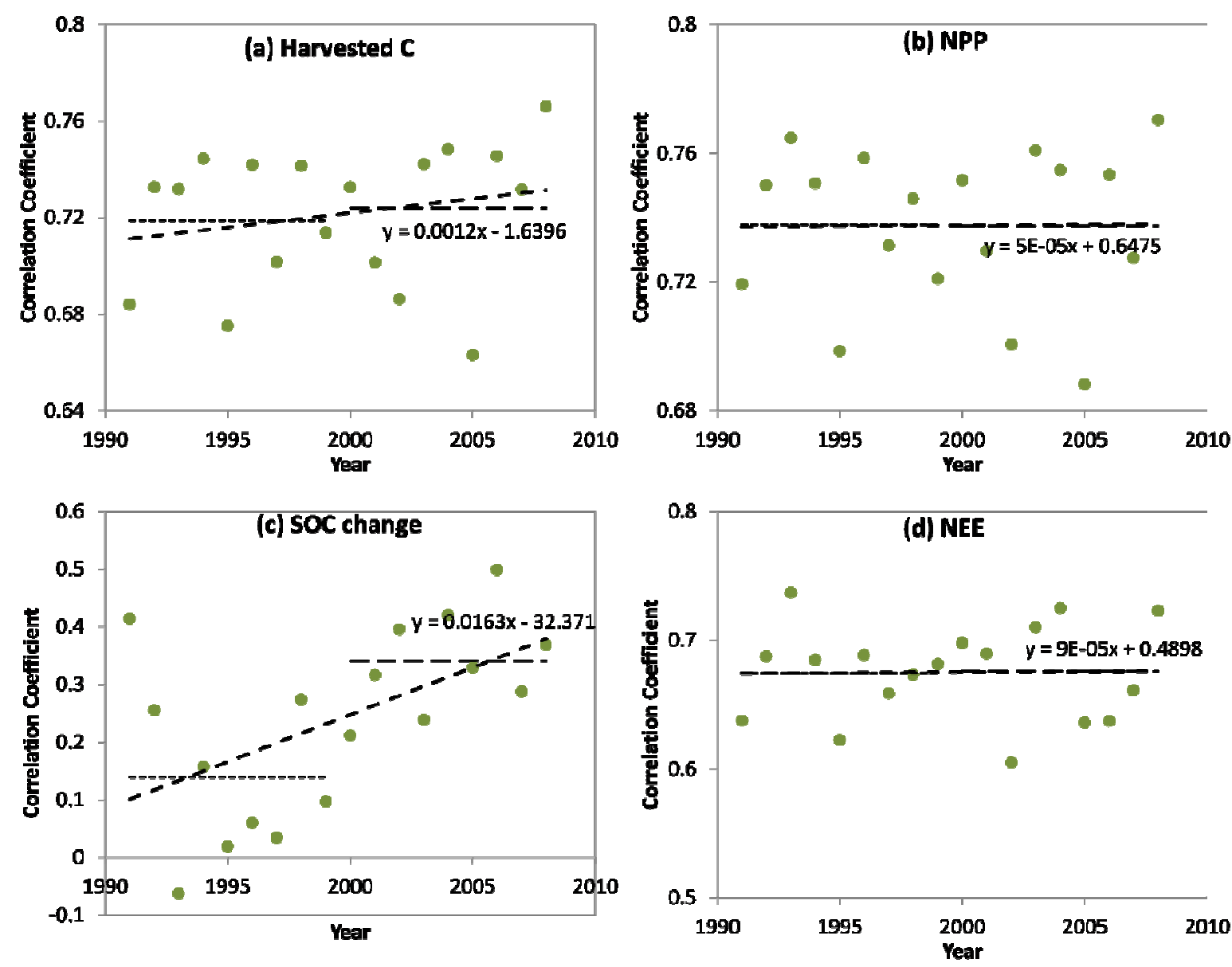

961 Figure 5. Time series of annual spatial correlation between EPIC simulated and inventory 962 estimated cropland carbon budget components over 1991-2008. 

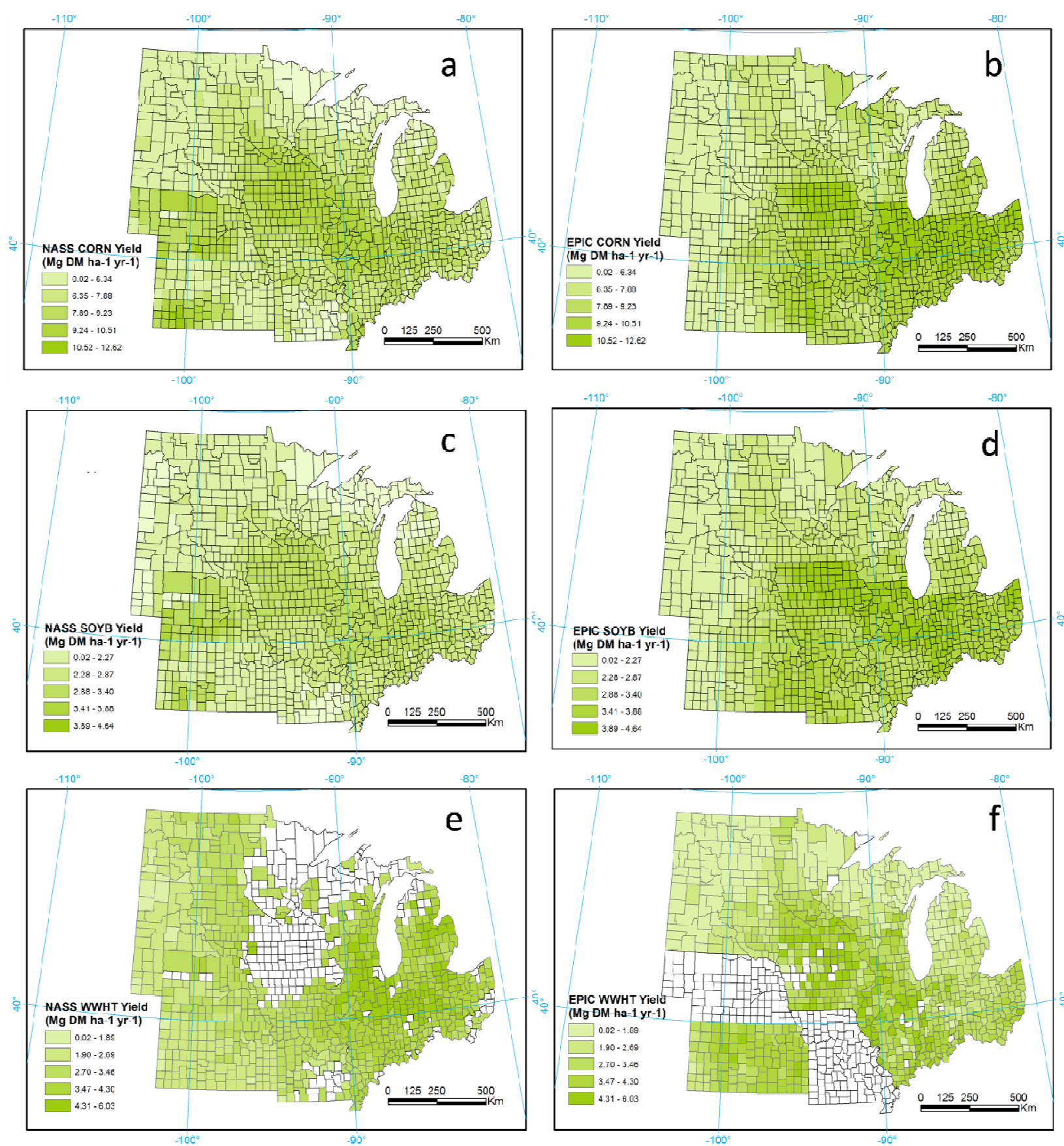

964 Figure 6. Spatial distribution of species-specific crop yield averaged over 2000-2008 for corn 965 (a-b), soybean (c-d), and winter wheat (e-f). (GAMS overestimates winter wheat's extent in Iowa 966 967 968 969 970 and Minnesota, and northern Wisconsin. In contrast, the crop rotation map used in GAMS leaves out winter wheat in Nebraska and Missouri. This is because we simplified crop rotations derived from multi-year CDLs, which merges crop rotations with minor areas into dominant ones. The winter wheat area in these two states represents less than $8 \%$ of the total cropland area, leading to its omission.) 

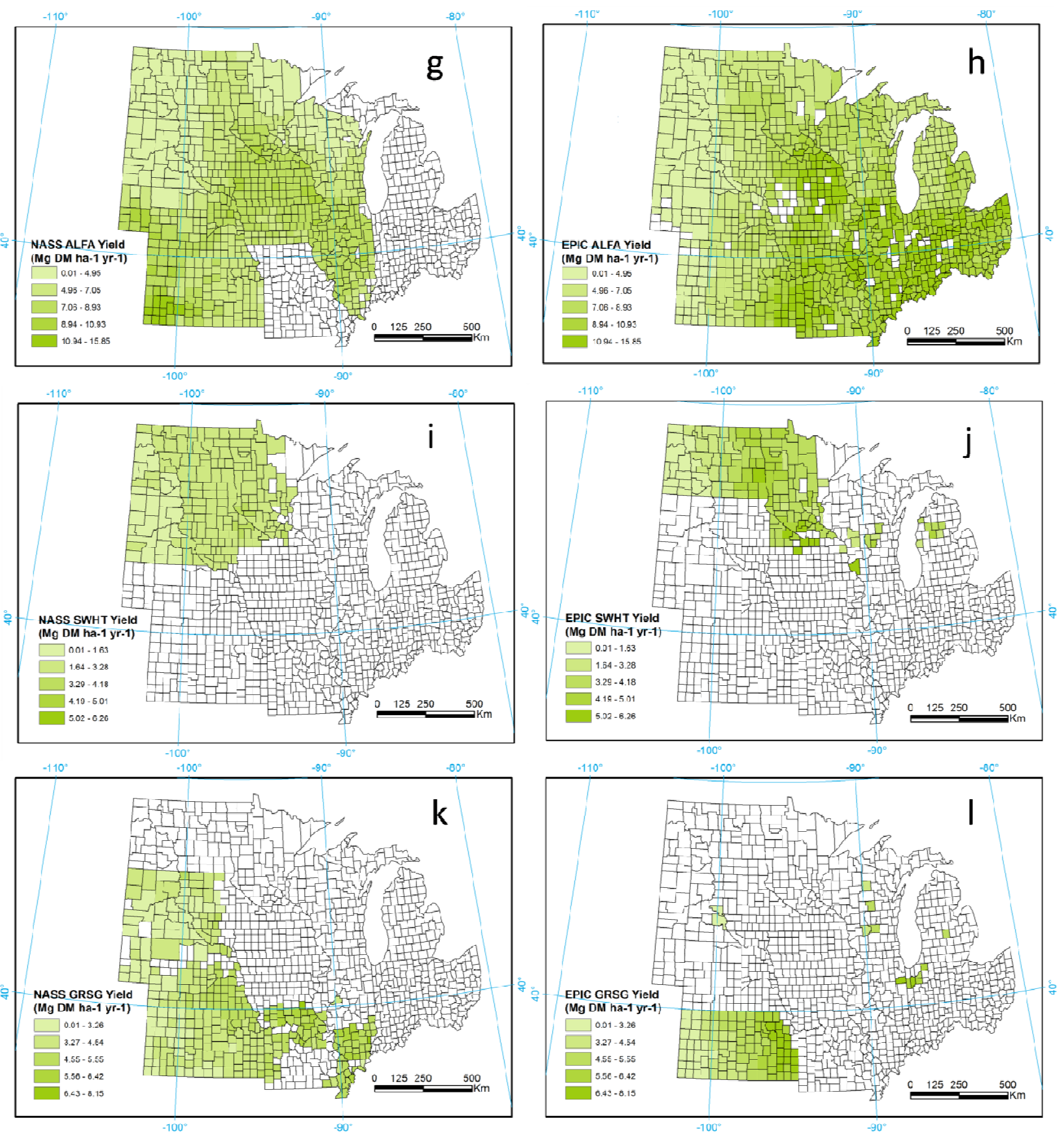

972 Figure 7. Spatial distribution of species-specific crop yield averaged over 2000-2008 for alfalfa 973 (g-h), spring wheat (i-j), and sorghum (k-1). (The NASS started to report alfalfa yield and area 974 data in 2009 for Missouri, Indiana, and Ohio; therefore (g) does not show the presence of alfalfa 975 in these states; The underestimation of spring wheat in South Dakota is because it is a minor crop 976 and was removed during the process of simplifying crop rotation; similarly the missing extent of 977 sorghum in South Dakota and Nebraska is also due to the crop rotation simplification that results 978 in the loss of crops with small area.) 

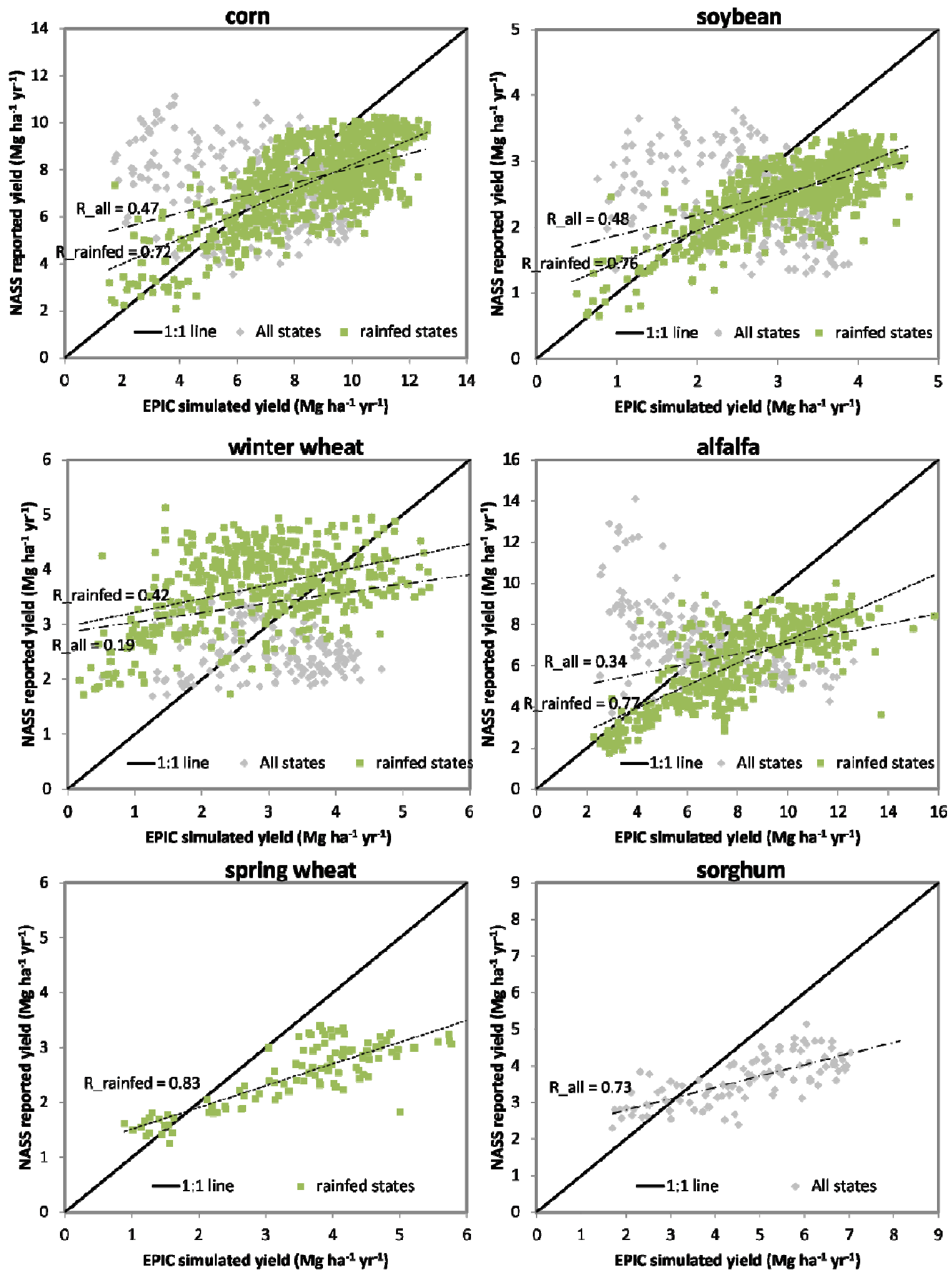

Figure 8. Spatial correlation between EPIC simulated and NASS reported multi-year average (2000-2008) species-specific crop yield. (R_all is calculated with data from all counties, while R_rainfed is derived from counties other than Kansas and Nebraska). 

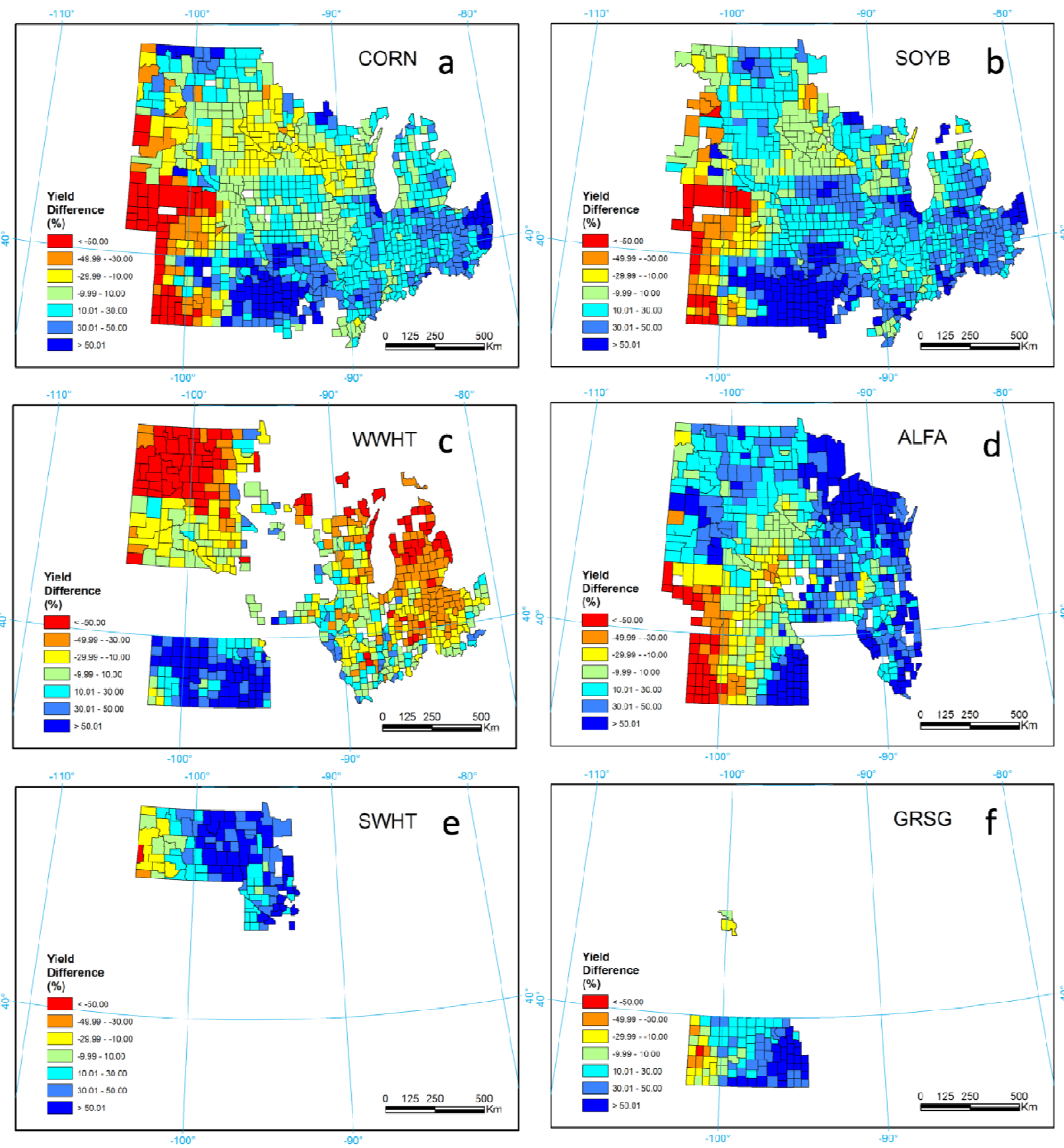

984 Figure 9. Spatial distribution of species-specific bias in EPIC simulated multi-year average 985 (2000-2008) crop yield. (Only those counties with concurrent EPIC simulated and NASS 986 reported data are shown.) 

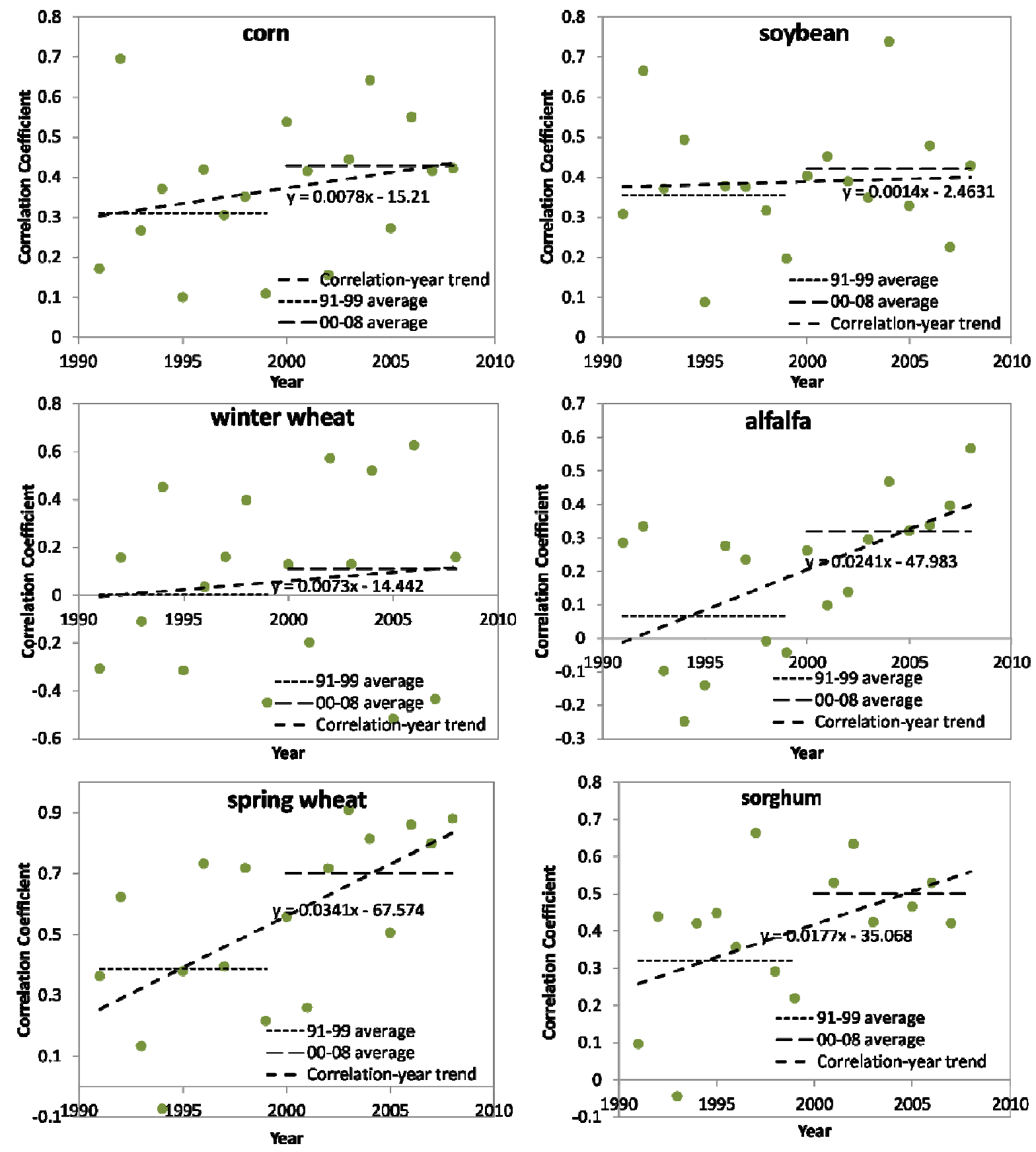

988 Figure 10. Time series of annual spatial correlation between EPIC simulated and NASS 989 reported species-specific crop yield over 1991-2008. 
991 Figure 11. Spatial correlation between simulated and NASS reported multi-year average (200026

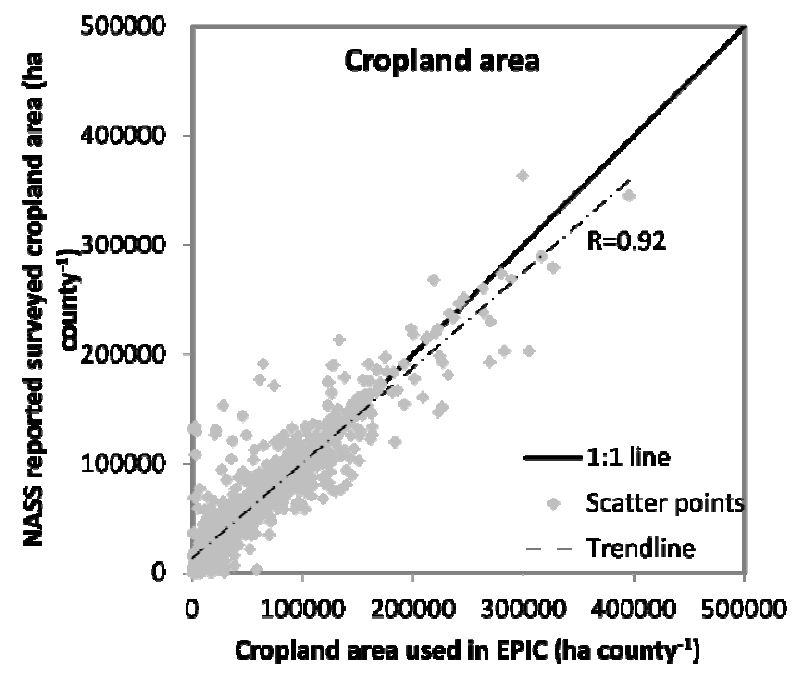

992 2008) total cropland area. 

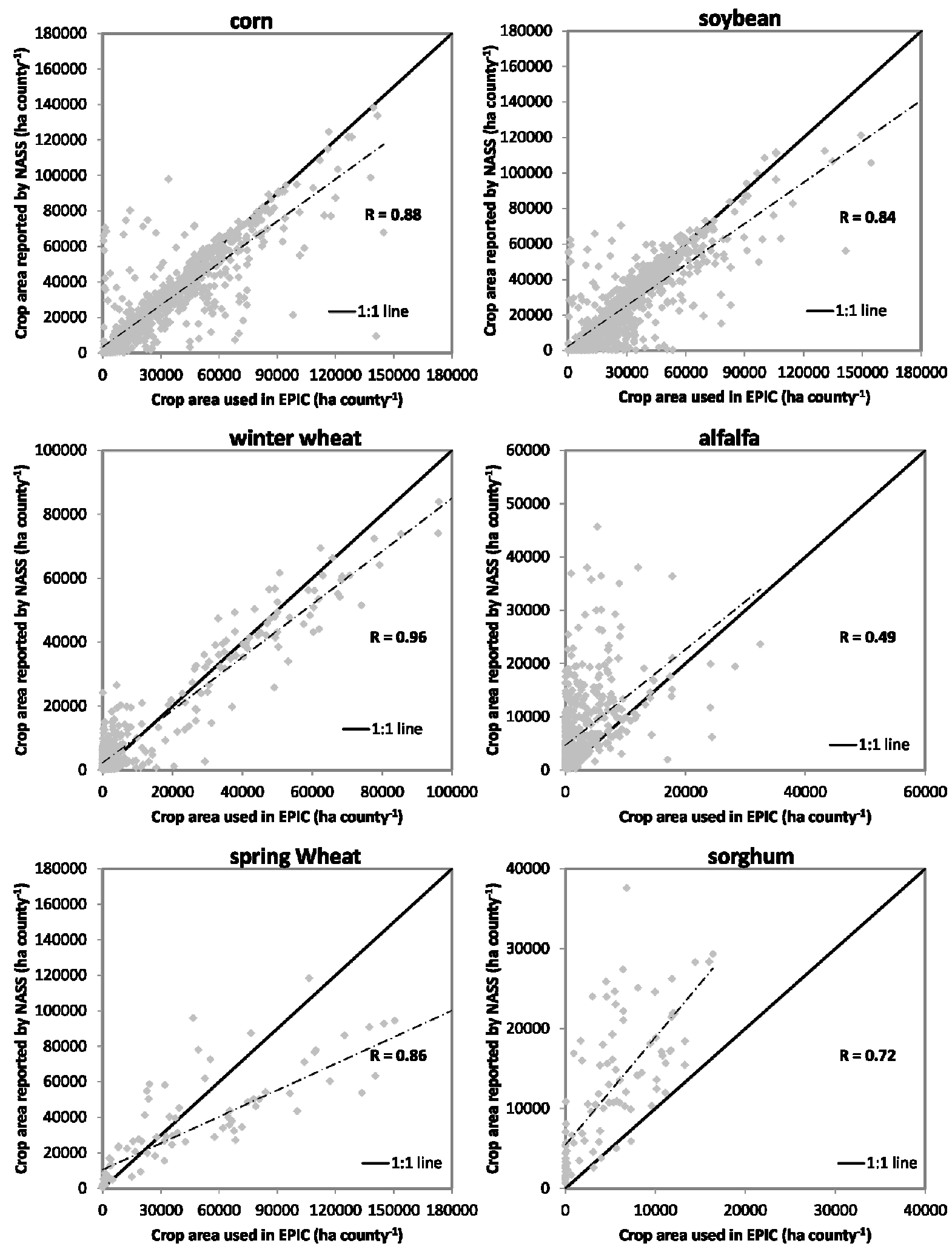

Figure 12. Spatial correlation between simulated and NASS reported multi-year average (2000995 2008) species-specific cropland area. 

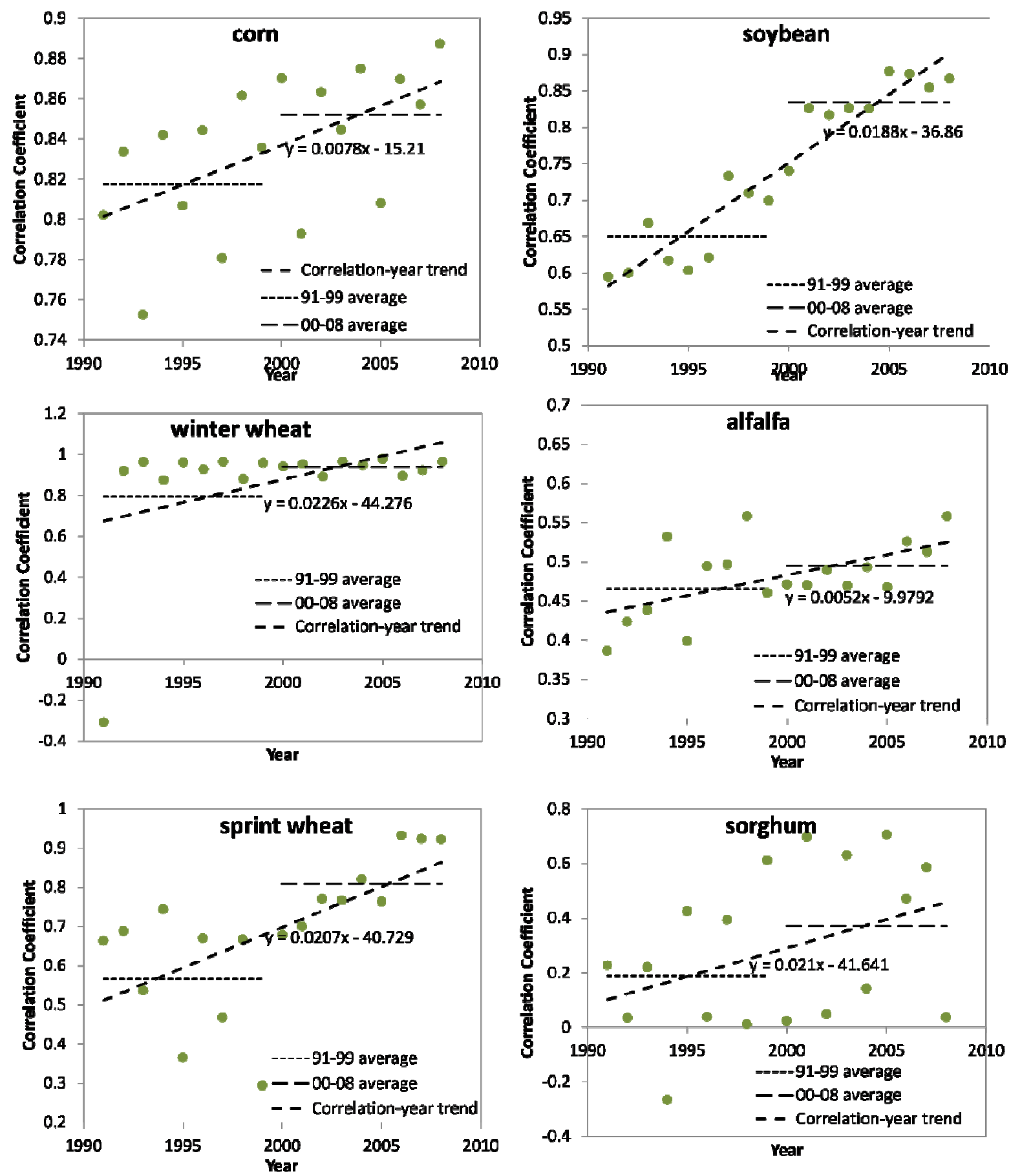

Figure 13. Time series of annual spatial correlation between simulated and NASS reported 998 species-specific cropland area over 1991-2008. 